\title{
Associations between sociodemographic factors, health spending, disease burden, and life expectancy of older adults (70 + years old) in 22 countries in the Western Pacific Region, 1995-2019: estimates from the Global Burden of Disease (GBD) Study 2019
}

\author{
Alex Molassiotis · Stephen W. H. Kwok • \\ Angela Y. M. Leung $\cdot$ Stefanos Tyrovolas
}

Received: 9 February 2021 / Accepted: 17 November 2021 / Published online: 8 January 2022

(C) The Author(s) 2022

\begin{abstract}
The needs of the aging populations are putting increasing burden on healthcare particularly in the Western Pacific Region (WPR), which is the home of aging economies such as Hong Kong and Japan alongside rapid increases in older people in low- and middle-income countries (LMICs). However, little is known about the associations between sociodemographic factors, disease burden, and life expectancy in WPR. The current study conducted secondary analysis on the Global Burden of Disease (GBD) estimates of populations aged 70 years and older in WPR countries between 1995 and 2019. Correlation tests, linear mixed regressions and generalized additive mixture models were run to examine the associations of interest. Unsupervised machine learning was conducted to segment the data automatically, at cluster analysis. The sociodemographic development index was found an important factor to the disease burden in terms of
\end{abstract}

Supplementary Information The online version contains supplementary material available at https://doi. org/10.1007/s11357-021-00494-z.

A. Molassiotis $(\bowtie) \cdot$ S. W. H. Kwok · A. Y. M. Leung ·

S. Tyrovolas

School of Nursing, The Hong Kong Polytechnic

University, Hung Hom, Kowloon, Hong Kong SAR

e-mail: alex.molasiotis@ polyu.edu.hk

S. Tyrovolas

Parc Sanitari Sant Joan de Déu, Fundació Sant Joan de

Déu, CIBERSAM, Barcelona, Spain
Years Lived with Disability (YLD) rate and mortality rate among older adults. YLD rate and mortality rate of non-communicable diseases (NCDs) attributable to different risk groups were significant contributors to higher expectation of Lost Healthy Years (LHE) and shorter life expectancy respectively in the context of rising YLD rate, particularly in LMICs. Three clusters of countries with similar characteristics were identified. NCDs were the most significant contributors to shorter life expectancy within which the time living in poor health did not improve. Better management of NCDs in aging populations should be emphasized in all countries. The country clusters may help in a more regional strategic planning.

Keywords Aging - Older adults - Western Pacific . Non-communicable diseases · Life expectancy ·

Disease burden $\cdot$ Sociodemographic factors

\section{Introduction}

The global population is generally aging in the last 30 years. Life expectancy at birth rose from around 67 years in 2000 to 73.5 years in 2019 [1]. However, ageing is followed by age-associated diseases and the healthcare needs and costs incurred have likely been an increasing burden in this population. In the Western Pacific Region, ageing-related epidemiological data 
allowing healthcare planning is scarce but the healthcare needs could be increasingly high. There is a significant demographic shift in the Western Pacific region in which those over the age of 60 years old outnumber those less than 5 years; the ageing index is among the highest in the low and middle income countries (LMICs) in the region, and in many of the countries of the region the population of older people will double by 2030 [2]. For instance, Japan has the second longest life expectancy in the world after Hong Kong SAR, China, and the longest life expectancy among OECD countries $[3,4]$ with a rapidly increasing older population. However, the transition to an ageing population in LMICs is much faster than that of the higher income countries in the region. Developed economies have higher sociodemographic index (SDI), a measure of a country's level of development, than developing nations [5]. The SDI was found to be positively associated with life expectancy at the global level [1]. However, data from the Western Pacific region, with its particular ageing society characteristics, diverse cultures and healthcare systems, the size of its population (particularly rural population) and with the majority of the countries being LMICs, will be useful for regional planning.

Given an estimated life expectancy, a key research interest is the proportion of it that would be lived in good health. The GBD 2019 Demographics Collaborators [1] found that both the healthy life expectancy (HALE) and the equivalent years of healthy life lost increased along with SDI or time. The LHE (expectation of Lost Healthy Years) is the product of life expectancy and LHE fraction, which is estimated from Years Lived with Disability (YLD) per capita [6, 7]. YLDs from NCDs and injuries have been increasingly contributing to burden of diseases since 1990 [7]. The findings indicated that NCDs is becoming prevalent in both developed and developing countries.

Disability Adjusted Life Years (DALYs) is a unit of disease burden in GBD studies. It is the sum of the YLD rate and the product of mortality rate and standard life expectancy [7,8]. Overall, the annualised rate of change in DALY rate fell when SDI increased [7]. However, improvements in age-standardised DALY rates have begun to slow down or reverse in high SDI economies [7]. NCDs remained to be significant contributors to disease burden. For instance, among those aged 50 or above in 2019, stroke and ischaemic heart disease were the top-ranked causes of DALYs [7], and high systolic blood pressure was the leading risk factor for attributable DALYs [9].

In the period between 1995 and 2016, the global health-spending rose by 4-6\%, and the governments increasingly made the largest contributions [10, 11]. In the Western Pacific Region, the Japanese achieved universal health coverage early in the 1960s [12]. The healthcare providers were reimbursed by the government through public insurance based on a nationally uniform fee which was set and revised by the government [13]. At the same time, the co-payment rate was as low as around 14\% [2], which was comparable to the $18 \%$ in Australia [14]. On the other hand, some developing countries have begun increasing their coverage rates. In the Philippines, the coverage rate rose from 70 to $90 \%$ between 2010 and 2016 [15]. In China, the coverage rate climbed from around $30 \%$ in early 2000s to over $90 \%$ in 2010 [16]. Moreover, the Chinese government started implementing time-ofservice co-payment programmes in one hundred cities since 2014 [17].

By implementing the policy of universal health coverage, the health-related financial burden on governments might inevitably grow alongside the rising disease burden associated with ageing populations. In other words, the increase in disease burden could be a factor to additional health spending which needs to be controlled. Zhai et al. [18] projected the Chinese data and showed that spending on NCDs would rise to at least three fourths of the total health spending by 2035 , and the expenditure might be reduced if the prevalence rates of risk factors such as smoking and hypertension could be lowered.

Nevertheless, given that countries with higher SDI would have higher income and lower disease burden than economies with lower SDI, the associations between health spending and YLD rates as well as mortality rates, which are determinants of life expectancy and disease burden, require further study. Moreover, the relative strength and significance of associations between the YLD rate and mortality rate of level 1 risk-cause pairs and the LHE and life expectancy respectively need to be investigated. Data with respect to locations and sexes in addition to other features such as sociodemographic factors, health spending, disease burden, and life expectancy at older ages might be segmented into clusters to which the countries belong, which may be important for regional planning. The current data on ageing issues 
in the Western Pacific Region, with the exception of high-income countries, is scarce. This is probably a result of that a majority of the countries in this region were developing ones which had to deal with other health priorities, had shorter life expectancy than developed countries, and lacked an urgency in collecting such data as in the western industrial world. Hence, the aim of the current study was to investigate the proposed associations between these features; as well as to identify clusters of countries for generalizable health planning and interventions in the Western Pacific Region.

Study objectives

1. To assess life expectancy and healthy life expectancy in those 70 years old and above in Western Pacific region countries.

2. To identify clusters of Western Pacific countries with similar ageing-related characteristics and health risks that would allow regional health policy initiatives rather than country-based ones.

3. To compare the differences in sociodemographic factors, disease burden, and life expectancy between clusters of Western Pacific countries in those over 70 years.

4. To analyse sociodemographic factors and healthcare spending associated with mortality and YLDs attributable to epidemiological risk factors in those over 70 years.

5. To identify the strength of associations between mortality and YLDs and life expectancy in the Western Pacific population over 70 years old.

\section{Methods}

GBD measures, cause list, and Western Pacific Region

We analysed results of the GBD 2019 study (which includes data from 1995 to 2019) to evaluate Western Pacific trends in epidemiological patterns and disease burden as well as their relationship with sociodemographic factors and health spending for the population aged above 70 years. The analyses employed established GBD 2019 summary measures of morbidity and mortality, including death rates, YLDs, LE, HALE and LHE at $70+$ years old. Seventy years and older is the GBD cut-off used to define older age. This threshold was selected based on availability of age groups in the GBD study (reflecting only the population over 65 years old). Additional details of methods used to estimate mortality rates, YLDs, including all other analytic approaches for the assessment of relative morbidity and mortality from individual diseases and injuries, are available in the latest GBD publications $[1,7,9]$. GBD data are publicly available and can be downloaded at http://ghdx.healthdata.org/gbd-resultstool. In the GBD 2019 study, causes of mortality and morbidity are defined using a four-level categorisation to deliver mutually exclusive and collectively exhaustive levels. The GBD 2019 study estimates the impact of 369 diseases and injuries as well as 87 risk factors between 1990 and 2019. The GBD study is organised by a geographical categorisation of super-regions and regions, with 204 countries and territories assigned within these areas. Within this topographical categorisation, the GBD study estimates seven fatal and nonfatal causes at Level 1, 22 at Level 2, 169 at Level 3, and 297 at Level 4. The full GBD cause hierarchy, including corresponding International Classification of Diseases (ICD)-9 and ICD-10 codes, is published in detail in previous GBD publications [19, 20]. For the current study only 22 Western Pacific countries were included in the analysis. These were countries in the East Asia (China, Mongolia, Japan, and South Korea); countries in the Southeast Asia (Cambodia, Laos, Vietnam, the Philippines, Malaysia, Brunei, and Singapore); and countries in the Oceania (Australia, New Zealand, Papua New Guinea, Fiji, Kiribati, Marshall Islands, the Federated States of Micronesia, Samoa, Solomon Islands, Tonga, and Vanuatu).

Mortality, life expectancy, and healthy life expectancy estimates

GBD mortality is estimated using standardized modelling processes-most commonly, the Cause of Death Ensemble model, which uses covariate selection and out-of-sample validity analyses and generates estimates for each location-year, age group, and sex. Additional details, including model specifications and data availability for each cause-specific model, can be found in the GBD 2019 mortality and causes of death publications [1]. In the current study we used the mortality rates for those $70+$ years old covering information for the period 1995 to 2019. For the calculation of LE, the GBD is using a specific model life table system (which 
identifies a reference table of each location, year, and sex, based on the nearest matches in the GBD empirical life table database) [1]. Using the GBD 2019 dataset in the current study, mean life expectancy (LE at $70+$ ) was used by our team, as the average expected years of life remaining at age 70-94 years from 1995 to 2019. GBD also uses HALE to estimate the number of years that people can expect to live in good health [21]. In a similar way as abovementioned for LE at $70+$ we estimated the HALE at 70+ using the age groups 70-94 from 1995 to 2019. Expectation of Lost Healthy Years (LHE, =LE-HALE) at $70+$ is the expected years of life living in poor health for those between 70-94 years old, and the fraction of LHE at 70+ is the proportion of LHE divided by LE at $70+[6]$.

Years lived with disability and risk factors

GBD study uses epidemiological data from systematic literature reviews, health surveys, surveillance systems, disease registries, and hospital and claims databases to generate cause-specific and sequela-specific prevalence and incidence estimates. GDB generated these estimates using a variety of modelling approaches, of which Bayesian meta-regression compartmental modelling in DisMod-MR 2.1 was the most common [22]. GBD then used a microsimulation framework to adjust for comorbidities and calculated YLDs for each cause by multiplying prevalence and corresponding disability weights for each sequela of each cause [23, 24]. In this research work we used the YLDs rates focused specifically for the population 70+ years old [7] from 1995 to 2019. The GBD 2019 comparative risk assessment framework classified each of 87 risk factors and clusters of risk factors into one of three categories: behavioral, environmental/ occupational, or metabolic. Data on risk factor exposure levels were identified, evaluated, and modelled in the GBD study using similar approaches to nonfatal models. Quantitative relative risk was estimated for each riskoutcome pair, and population-attributable fraction statistics were calculated using standard GBD CRA methods [9]. We used these risk outcome paired estimates for the population 70+ and for the years 1995-2019.

Socioeconomic, healthcare access and quality indicators, health spending and other variables

To further assess the effects of socioeconomic factors, health system performance on Western Pacific health metrics, we employed the Socio-demographic Index (SDI), the Healthcare Access and Quality (HAQ) Index and healthcare spending estimates respectively. Also, other variables such as years of education per capita and the population fertility rate were used. The mean years of education per capita was the average years of schooling and single-year distribution of educational attainment annually by sex for adults ages 25-29 for 1995 to 2019 [25]. The fertility rate was the annual estimates for total fertility under 25 years (TFU25) per 1000 women for 1995 to 2019 [26]. SDI is a composite indicator based upon the country-level income per capita, the average educational attainment among individuals over age 15 , and the total fertility rate among women under 25. The SDI ranges from 0 to 1 [7]. Each country's income level (high (HICs)-, middle (MICs)-, low (LICs)-) was based on the World Bank's classification [27]. HAQ Index is a composite metric developed following GBD 2016 that is based on comparative mortality rates for health-care-sensitive diseases, standardized to risk exposure level, and is meant to quantify the overall performance of health systems. The HAQ Index ranges from 0 to 100 [28]. The measures of healthcare spending consist of total healthcare spending (THS) per capita, THS per GDP, government health spending per THS, prepaid private spending per THS and out-of-pocket (OOP) spending per THS for 1995 to 2019 [29, 30].

Data analysis

Cluster analysis: Two-step cluster analysis was used to explore the number and characteristics of clusters in the time series data from 1995 to 2019 with respect to Western Pacific Region countries. The categorical variables were country and sex. The continuous variables were GDP per capita, education years, fertility rate, THS per capita, THS per GDP, government spending per THS, prepaid private spending per THS, OOP spending per THS, HAQI frontier, YLD rate, mortality rate, HALE, and LHE fraction at 70+ years old. A pre-cluster step was used a sequential clustering approach, which followed by the procedure of constructing a modified cluster feature $(\mathrm{CF})$ tree. More information on the cluster analysis can be found in the appendix. Correlation analysis: Associations among several factors such as the sociodemographic factors, health spending, disease burden and life expectancy at 70+ were tested with Spearman's 
rank-order correlation tests. Spearman's correlation was tested on the pooled dataset as well as for years 1995 and 2019. All P-values are based on two-sided tests. A P-value $<0.05$ was considered as significant. Longitudinal Regression analysis: Analysis was based on time-series from 1995 to 2019, in order to ensure the maximum data availability. Linear mixed effects (LME) models and generalized additive mixture (GAM) models were built to estimate the parameters of YLD rate and mortality rate, LHE, and life expectancy at $70+$ with respect to several characteristics (more detail on the models are presented on the supplementary appendix 1). The software used for correlation tests and cluster analysis was
IBM SPSS 25 (Armonk, NY: IBM Corp.). R 4.1.0 (Vienna, Austria: R Foundation) on RStudio 1.4.1717 (Boston, Massachusetts: RStudio) was used to run LME and GAM models.

\section{Results}

Life expectancy and healthy life expectancy at the age of 70 years

Table 1 shows LE and HALE at age 70years. The highest LE in males was observed in Singapore, followed by Japan, Australia, New Zealand and Korea
Table 1 Life expectancy (LE) and healthy life expectancy (HALE) in Western Pacific countries at the age of 70 years old, for 2019

\begin{tabular}{|c|c|c|c|c|}
\hline Country & LE (Male) & HALE (Male) & LE (Female) & $\begin{array}{l}\text { HALE } \\
\text { (Female) }\end{array}$ \\
\hline China & 11.82 & 8.87 & 15.13 & 10.59 \\
\hline Cambodia & 10.2 & 7.31 & 12.18 & 8.58 \\
\hline Laos & 10.52 & 7.71 & 12.12 & 8.67 \\
\hline Malaysia & 12.18 & 8.79 & 13.26 & 9.35 \\
\hline Philippines & 11.53 & 8.35 & 13.46 & 9.54 \\
\hline Vietnam & 10.73 & 7.83 & 14.34 & 10.28 \\
\hline Fiji & 9.39 & 6.58 & 11.51 & 7.93 \\
\hline Kiribati & 8.32 & 5.99 & 9.15 & 6.54 \\
\hline Marshall Islands & 10.13 & 7.28 & 10.06 & 6.97 \\
\hline Micronesia & 9.19 & 6.75 & 9.77 & 6.92 \\
\hline Papua New Guinea & 10.05 & 7.31 & 11.4 & 7.87 \\
\hline Samoa & 11.44 & 8.33 & 11.9 & 8.31 \\
\hline Solomon Islands & 8.13 & 6.01 & 8.32 & 5.97 \\
\hline Tonga & 11.01 & 8.12 & 14.4 & 10.14 \\
\hline Vanuatu & 9.76 & 7.18 & 10.54 & 7.42 \\
\hline Mongolia & 9.31 & 7.14 & 12.11 & 9.22 \\
\hline Brunei & 9.72 & 7.01 & 12.76 & 9.1 \\
\hline Japan & 16.47 & 12.33 & 20.41 & 14.86 \\
\hline Korea & 15.13 & 11.23 & 18.32 & 13.34 \\
\hline Singapore & 16.74 & 12.7 & 19.45 & 14.5 \\
\hline Australia & 15.96 & 11.32 & 18.32 & 12.75 \\
\hline New Zealand & 15.47 & 11.05 & 17.56 & 12.31 \\
\hline Cook Islands & 12.57 & 8.88 & 14.74 & 9.99 \\
\hline Nauru & 8.95 & 6.51 & 9.8 & 6.84 \\
\hline Niue & 10.46 & 7.43 & 12.71 & 8.63 \\
\hline Palau & 10.25 & 7.3 & 11.33 & 7.75 \\
\hline Tuvalu & 10.78 & 7.9 & 10.93 & 7.63 \\
\hline
\end{tabular}

Data on this table are reflecting LE and HALE for the population at the age of 70 (age group 70-74), for 2019. LE and HALE information on the rest of the age groups for the period 1995 to 2019 can be found at http://ghdx.healthdata.org/gbdresults-tool 
Table 2 Centroids of clusters with respect to continuous inputs and cluster membership of countries in populations older than 70 years old in the Western Pacific Region, 1995-2019

\begin{tabular}{|c|c|c|c|c|c|}
\hline & Cluster 1 & Cluster 2 & Cluster 3 & Combined & Importance \\
\hline & $n=250$ & $n=544$ & $n=300$ & $N=1094$ & \\
\hline & Mean (SD) & Mean (SD) & Mean (SD) & Mean (SD) & \\
\hline $\begin{array}{l}\text { Total health spending } \\
\text { per capita in PPP }\end{array}$ & $3076(1135 \cdot 43)$ & $407 \cdot 36(585 \cdot 47)$ & $319 \cdot 66(278 \cdot 28)$ & $993 \cdot 15(1331 \cdot 44)$ & 0.9978 \\
\hline $\begin{array}{l}\text { Out-of-pocket spending } \\
\text { per THS }\end{array}$ & $0 \cdot 26(0 \cdot 13)$ & $0 \cdot 14(0 \cdot 07)$ & $0.48(0.09)$ & $0 \cdot 26(0 \cdot 17)$ & 0.9409 \\
\hline $\begin{array}{l}\text { Healthy life expectancy, } \\
\text { age } 70+\end{array}$ & $6 \cdot 82(0 \cdot 97)$ & $4 \cdot 25(0 \cdot 63)$ & $5(0 \cdot 52)$ & $5.04(1.23)$ & $0 \cdot 8794$ \\
\hline $\begin{array}{l}\text { Deaths per } 100 \mathrm{~K} \text {, all } \\
\text { risk-cause, age } 70+\end{array}$ & $2873 \cdot 65(820 \cdot 81)$ & $6733 \cdot 56(1374 \cdot 28)$ & $5340 \cdot 61(1192 \cdot 66)$ & $5469 \cdot 52(1954 \cdot 99)$ & 0.7301 \\
\hline HAQI frontier & $87.99(2.63)$ & $67 \cdot 96(10 \cdot 25)$ & $66 \cdot 8(9 \cdot 47)$ & $72 \cdot 22(12 \cdot 34)$ & $0 \cdot 512$ \\
\hline $\begin{array}{l}\text { Mean years of educa- } \\
\text { tion, age } 25-29\end{array}$ & $13 \cdot 56(1 \cdot 01)$ & $8 \cdot 86(2 \cdot 41)$ & $8 \cdot 24(2 \cdot 42)$ & $9 \cdot 76(3 \cdot 01)$ & $0 \cdot 5023$ \\
\hline $\begin{array}{l}\text { Fertility per } 1000 \text {, age } \\
10-24\end{array}$ & $0 \cdot 27(0 \cdot 15)$ & $1 \cdot 04(0 \cdot 37)$ & $0.93(0 \cdot 4)$ & $0.84(0.46)$ & $0 \cdot 4726$ \\
\hline $\begin{array}{l}\text { Government spending } \\
\text { per THS }\end{array}$ & $0 \cdot 64(0 \cdot 16)$ & $0 \cdot 67(0 \cdot 15)$ & $0 \cdot 37(0 \cdot 12)$ & $0 \cdot 58(0 \cdot 19)$ & 0.4529 \\
\hline $\begin{array}{l}\text { Prepaid private spend- } \\
\text { ing per THS }\end{array}$ & $0 \cdot 1(0 \cdot 05)$ & $0 \cdot 02(0 \cdot 03)$ & $0.09(0.05)$ & $0.06(0.06)$ & $0 \cdot 4061$ \\
\hline $\begin{array}{l}\text { YLDs per } 100 \mathrm{~K}, \text { all } \\
\text { risk-cause, age } 70+\end{array}$ & $8582 \cdot 29(1164 \cdot 86)$ & $11,641 \cdot 51(1834 \cdot 1)$ & $10,723 \cdot 56(934 \cdot 75)$ & $10,690 \cdot 7(1919 \cdot 99)$ & $0 \cdot 3907$ \\
\hline $\begin{array}{l}\text { GDP per capita, PPP } \\
\text { (current international } \\
\$)\end{array}$ & $38,233 \cdot 32(18,347 \cdot 31)$ & $10,214 \cdot 29(19,907 \cdot 8)$ & $6908 \cdot 81(6488 \cdot 84)$ & $15,710 \cdot 74(20,914 \cdot 68)$ & $0 \cdot 3296$ \\
\hline $\begin{array}{l}\text { Total health spending } \\
\text { per GDP }\end{array}$ & $0.07(0.02)$ & $0 \cdot 06(0 \cdot 04)$ & $0 \cdot 04(0 \cdot 01)$ & $0.06(0.03)$ & $0 \cdot 0735$ \\
\hline $\begin{array}{l}\text { LHE fraction, 70+ } \\
\text { years old }\end{array}$ & $0 \cdot 3(0 \cdot 02)$ & $0 \cdot 31(0 \cdot 02)$ & $0 \cdot 31(0 \cdot 02)$ & $0 \cdot 31(0 \cdot 02)$ & 0.0032 \\
\hline Countries & $\begin{array}{l}\text { Japan } \\
\text { Republic of Korea } \\
\text { Singapore } \\
\text { Australia } \\
\text { New Zealand }\end{array}$ & $\begin{array}{l}\text { Fiji } \\
\text { Kiribati } \\
\text { Marshall Islands } \\
\text { Micronesia (Federated } \\
\quad \text { States of) } \\
\text { Papua New Guinea } \\
\text { Samoa } \\
\text { Solomon Islands } \\
\text { Tonga } \\
\text { Vanuatu } \\
\text { Mongolia } \\
\text { Brunei Darussalam }\end{array}$ & $\begin{array}{l}\text { China } \\
\text { Cambodia } \\
\text { Lao People's } \\
\text { Democratic } \\
\text { Republic } \\
\text { Malaysia } \\
\text { Philippines } \\
\text { Viet Nam }\end{array}$ & & \\
\hline
\end{tabular}

Cluster analysis applied on 1995-2019 GBD data. Each location, by sex, by year, was considered a case. Silhouette measure of cohesion and separation $=0 \cdot 4$. THS total health spending. GDP gross domestic product. PPP purchasing power parity. HAQI frontier healthcare access and quality index computed based on relationship between HAQI and SDI. HALE healthy life expectancy. YLD years lived with disability. $L H E$ equivalent years of healthy life lost

but HALE was 3.9-4.64 years less than LE. In females the picture was similar, although China, Malaysia, Vietnam, Cook Islands and Tonga followed with relatively high LE. HALE was lower by $5+$ years in the high income countries for females with the same pattern across all countries, indicating that while females have longer LE at 70 years old, the years living in poor health also increase in these countries. 


\section{Clustering of countries and YLD and mortality country profiles}

In the exploratory cluster analysis, three clusters of countries were identified (Table 2) based on 15 input variables (Supplementary Fig. 1). The total health spending (THS) per capita in PPP and out-of-pocket spending per THS were the two most important inputs defining the clusters. THS per capita in cluster 1 (developed countries) was around eight and ten times of the THS in cluster 2 and 3 respectively. On the other hand, nearly half of the THS was contributed by out-of-pocket payment in cluster 3 , while the OOP spending contributed one fourth of the THS in cluster 1 . In cluster 2 , the percentage of THS attributed to OOP expenditure was only $14 \%$, much lower than that both the other clusters.

The importance of government spending, prepaid private spending and GDP per person were lower than that of OOP spending in the clustering. The THS contributed by the government was less important in the clustering, but the percentages were significant. Over two thirds of the THS in cluster 1 and 2 were paid by governments, while more than one-third of the THS was sponsored by the governments in cluster 3 . The contributions from prepaid private spending were much smaller, which were less than $10 \%$ of the THS, particularly in cluster 2. Though the GDP per capita in cluster 1 was much higher than the value in the other two clusters, the THS per GDP between clusters was similar ranging between 4 and $7 \%$.

Furthermore, HALE at $70+$ was also an important input in the clustering. The mean HALE was 7, 4, and 5 years in cluster 1,2 , and 3 respectively. Nonetheless, the LHE fractions at $70+$ were similar across clusters, which were nearly $30 \%$. The mortality rate, fertility rate, as well as YLD rate followed the reverse order where the rates in cluster 1 were the lowest and the rates in cluster 2 were the highest. Healthcare access and quality (HAQI) and years of education had moderately high level of importance to the clustering. The mean HAQI frontier in cluster 1 was 88 , which was higher than the 67 in the other two clusters. Furthermore, the years of education per capita in cluster 1 was the longest, while the education years in the other two clusters were shorter.

Concerning country-specific disease burden, a number of developing countries had higher YLD rate and mortality rate of NCDs than other countries. For instance, the YLD rate and mortality rate of NCDs attributable to metabolic risks were higher in Fiji than the other countries. Mongolia had higher mortality rates of NCDs attributable to behavioral risks than other nations. Moreover, the YLD rate of NCDs related to environmental/ occupational risks were higher in Cambodia, Laos, Papua New Guinea, and Vanuatu than the rates in other economies. Country profiles for their demographic and health-related characteristics as well as all risk factors in relation to YLD and mortality in the three clusters are shown in Figs. 1, 2 and 3 respectively. Of note in these figures is that SDI over time has been improving in all countries, the government spending per THS on the Pacific Islands in cluster 2 is extremely volatile as is the THS per GDP, the relatively low THS per capita both in cluster 2 and 3, the increasing life expectancy at age 70 which is more profound in cluster 1 (developed countries) and less so in cluster 2 countries, and HALE at $70+$ which show minimal change over time beyond cluster 1 (Fig. 1). Figures 2 and 3 show a clear rise in NCD-related risks in all three clusters but also the different risks across the 22 countries examined.

\section{Correlations}

The SDI, HAQI frontier, GDP per person, education years, fertility rate, and THS per capita had stronger correlations with the YLD rates of (1) Communicable, Maternal, Neonatal, and Nutritional Diseases (CMNNDs) associated with the level 1 risks (aggregate of environmental and occupational risks, behavioral risks, and metabolic risks), (2) NCDs attributable to environmental/ occupational risks, and (3) injuries related to metabolic risks than other factors (Table 3). On the other hand, the correlations between the sociodemographic variables and the mortality rates of CMNNDs and NCDs attributable to the level 1 risk groups were stronger than other correlations (Table 4). The YLD rates of (1) CMNNDs related to level 1 risks, (2) NCDs attributable to behavioral risks or environmental/ occupational risks, as well as (3) injuries associated with metabolic risks or environmental/ occupational risks had stronger correlations with life expectancy, HALE, and LHE at $70+$ than other YLD rates (Table 5). In addition, the associations between LHE fraction at $70+$ and the CMNNDs attributable to metabolic risks or 
Fig. 1 Graphs of sociodemographic and healthrelated variables over time by clusters, 1995-2019. $[G D P=$ gross domestic product. $P P P=$ purchasing power parity. $T H S=$ total health spending]

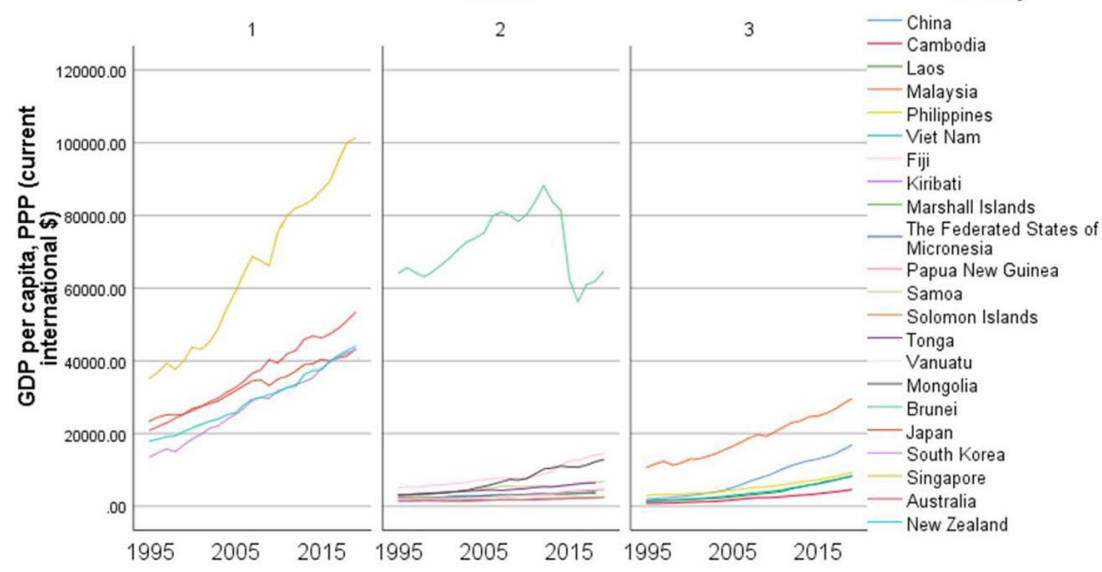

Year

b

Cluster Country

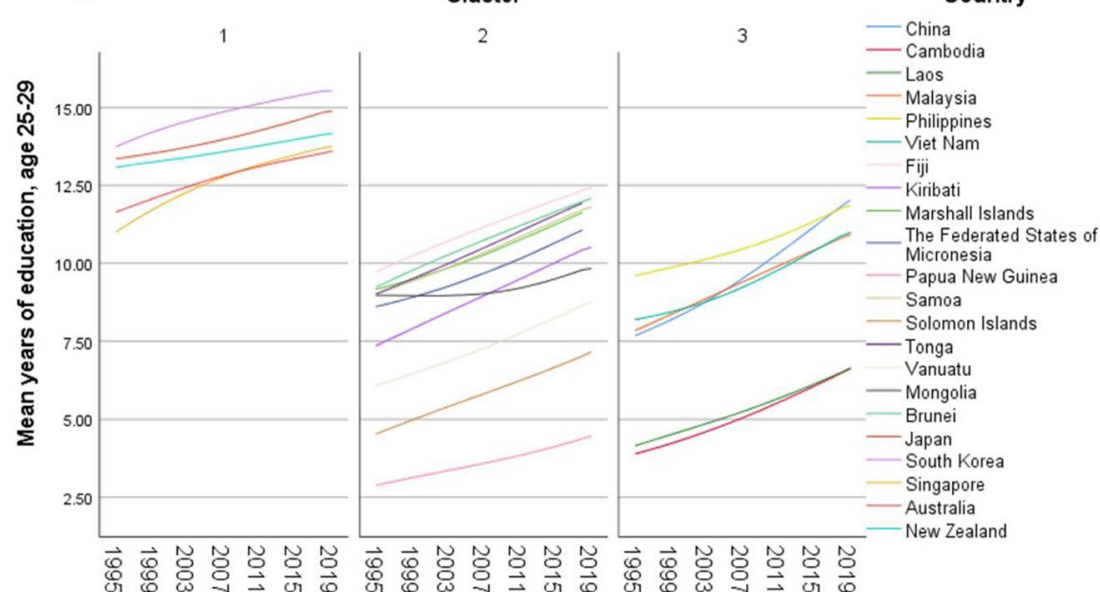

Year

C

Cluster

Country

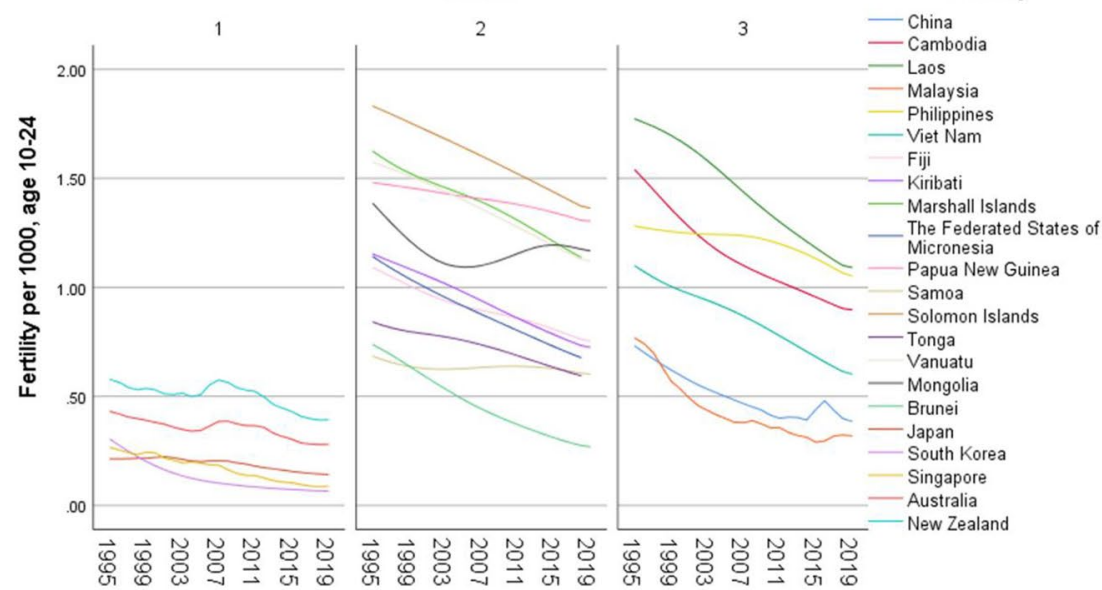

Year 
Fig. 1 (continued)

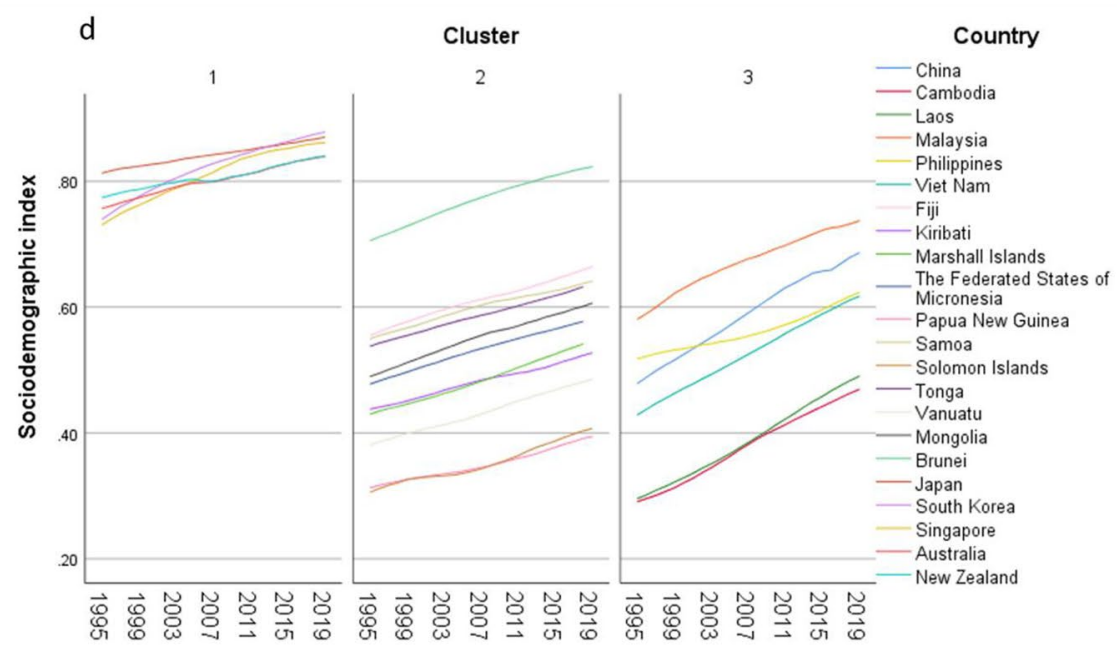

Year

e

Cluster

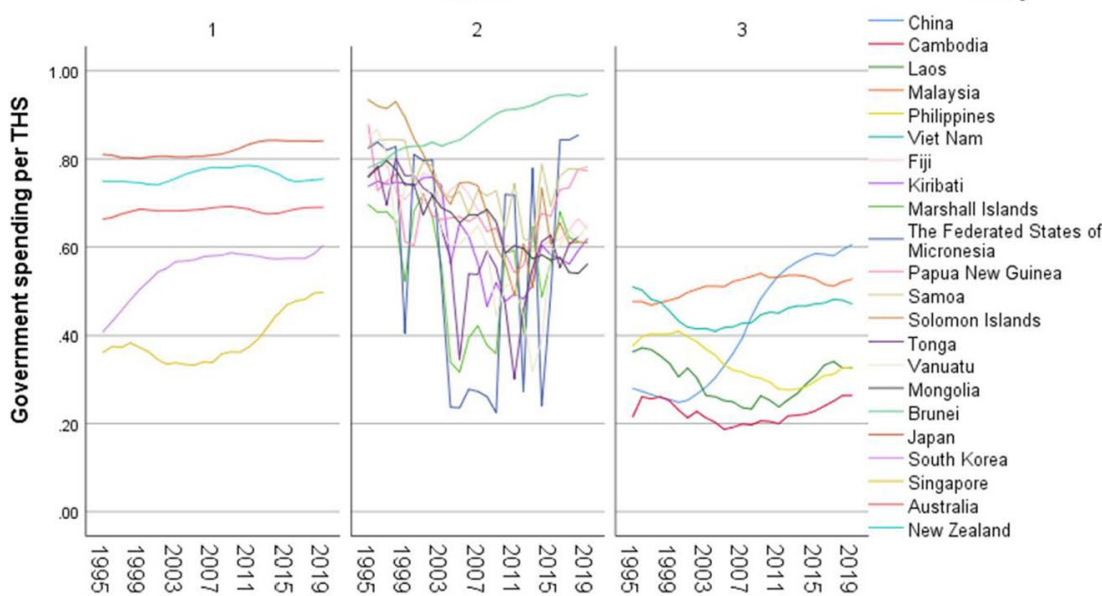

Year

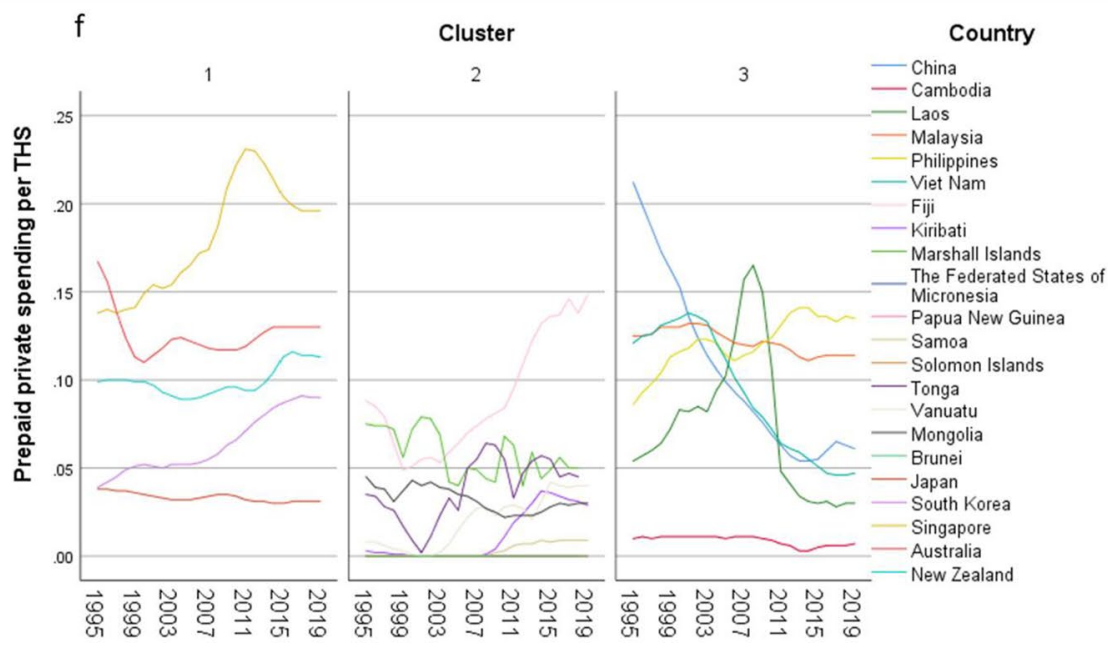

Year 
Fig. 1 (continued)

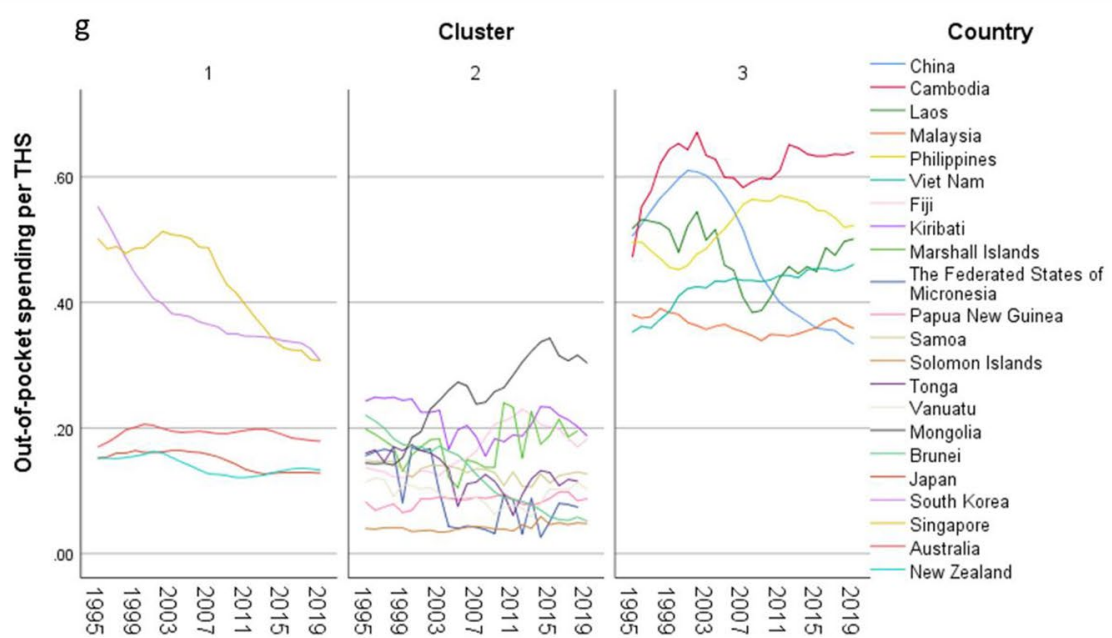

Year

h

Cluster

Country

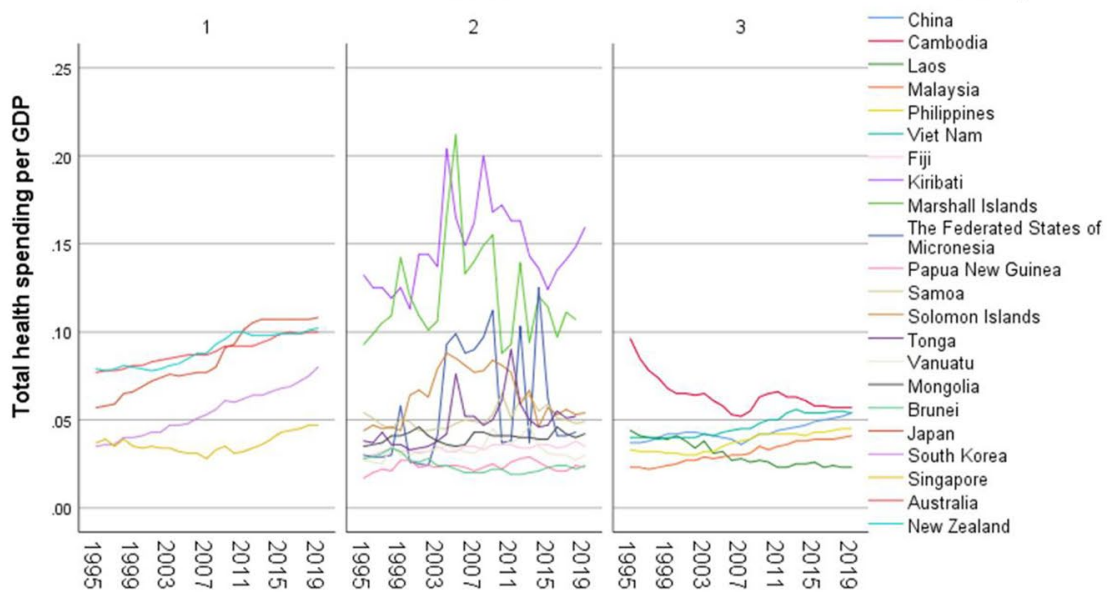

Year

Cluster

Country

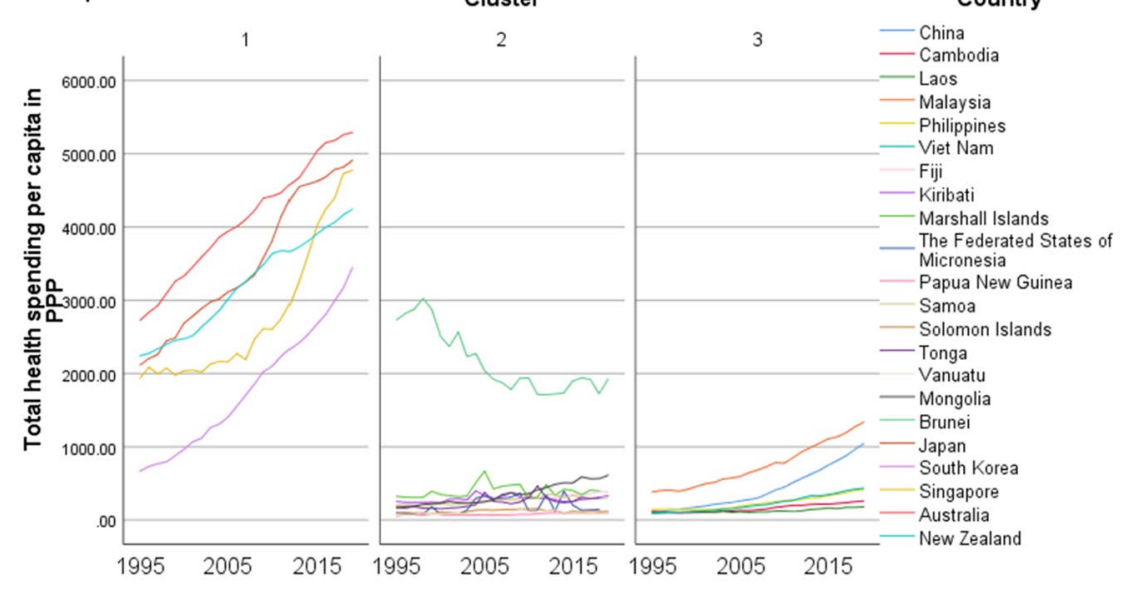

Year 
Fig. 1 (continued)

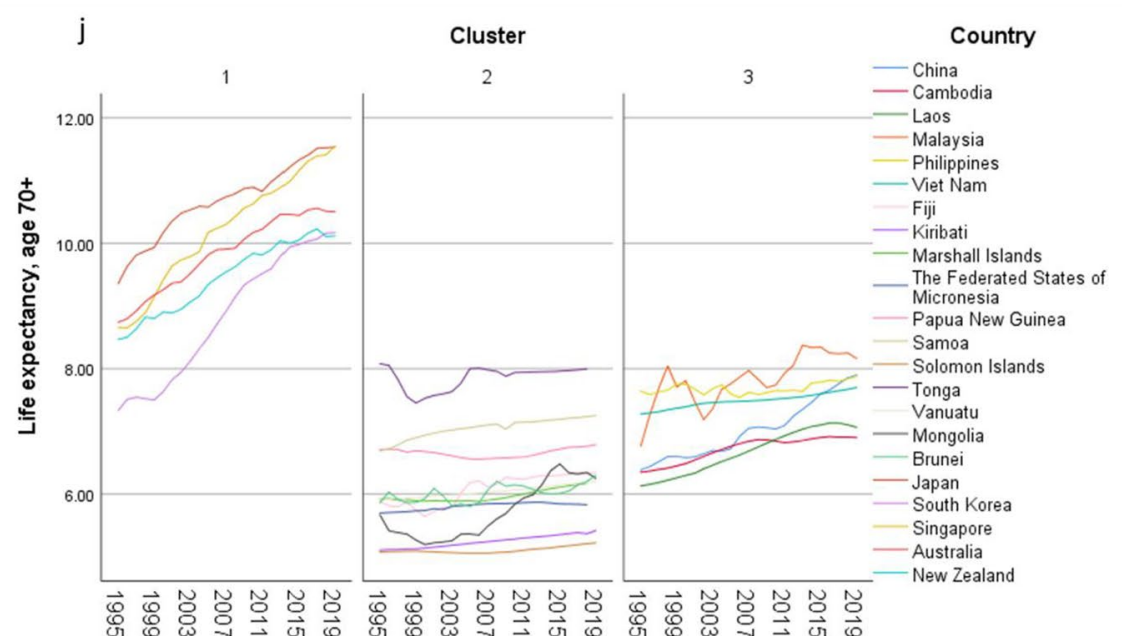

Year

k

Cluster

Country

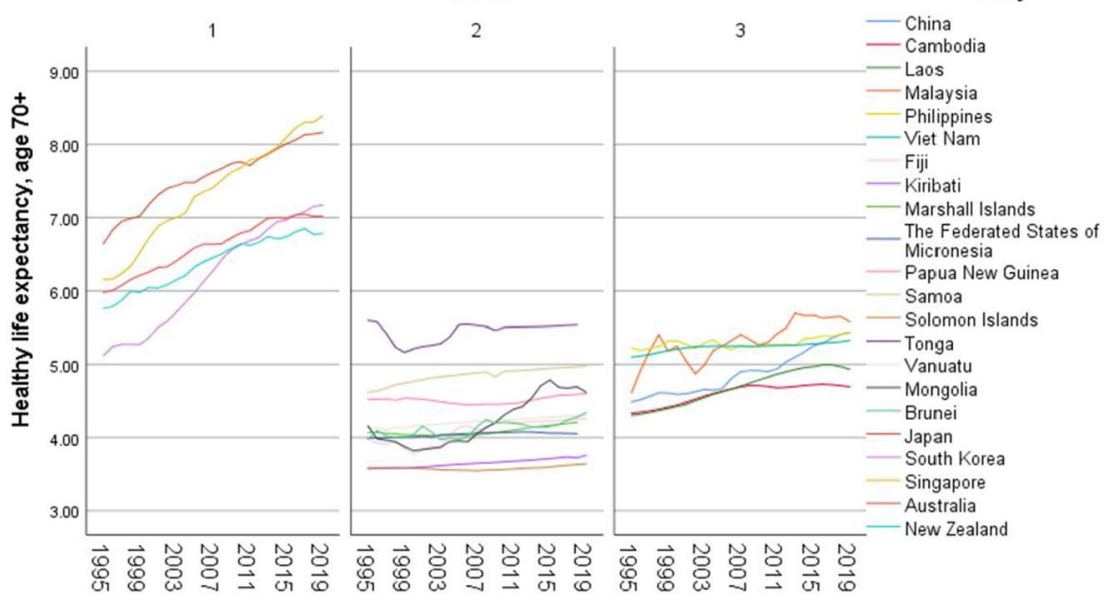

Year

I

Cluster

Country

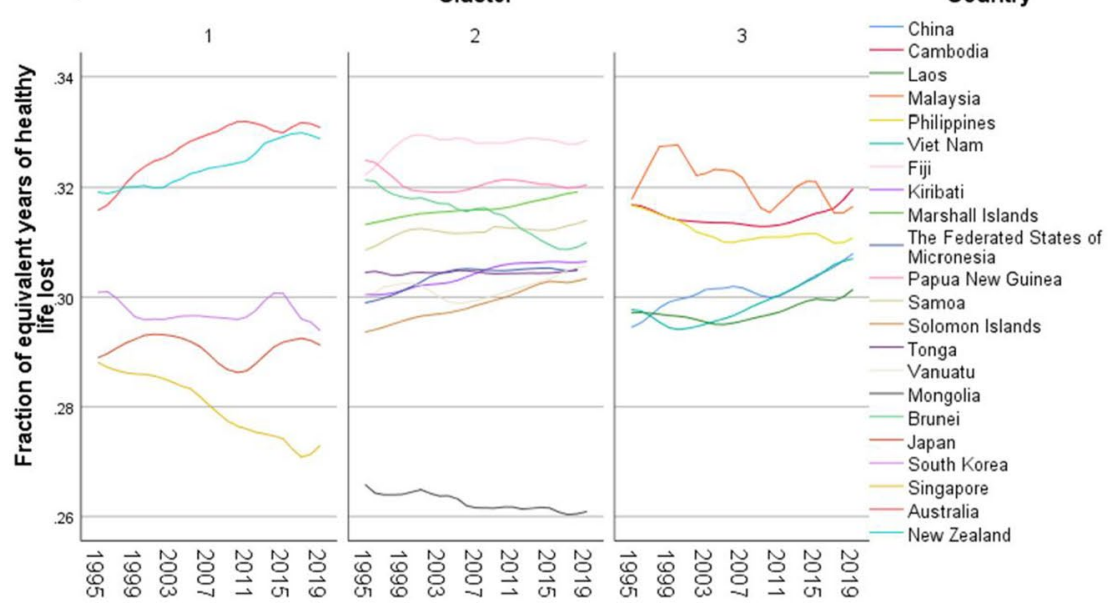


Fig. 2 Graphs of YLD rate (per $100 \mathrm{~K}$ ) risk factors over time by clusters in older adults, 1995-2019. YLD = years lived with disability. [Metabolic risks = i.e., high fasting plasma glucose, high cholesterol; high blood pressure; high BMI; low bone mineral density; impaired kidney function. Environmental /Occupational risks = i.e., unsafe water; sanitation; handwashing; air pollution; exposure to occupational carcinogens. Behavioural risks = i.e., child \& maternal malnutrition; tobacco use; alcohol use; drug use; dietary risks; intimate partner violence; childhood maltreatment; unsafe sex; low physical activity. $C M N N D=$ communicable, maternal, neonatal and nutritional diseases. $N C D=$ non-communicable disease]
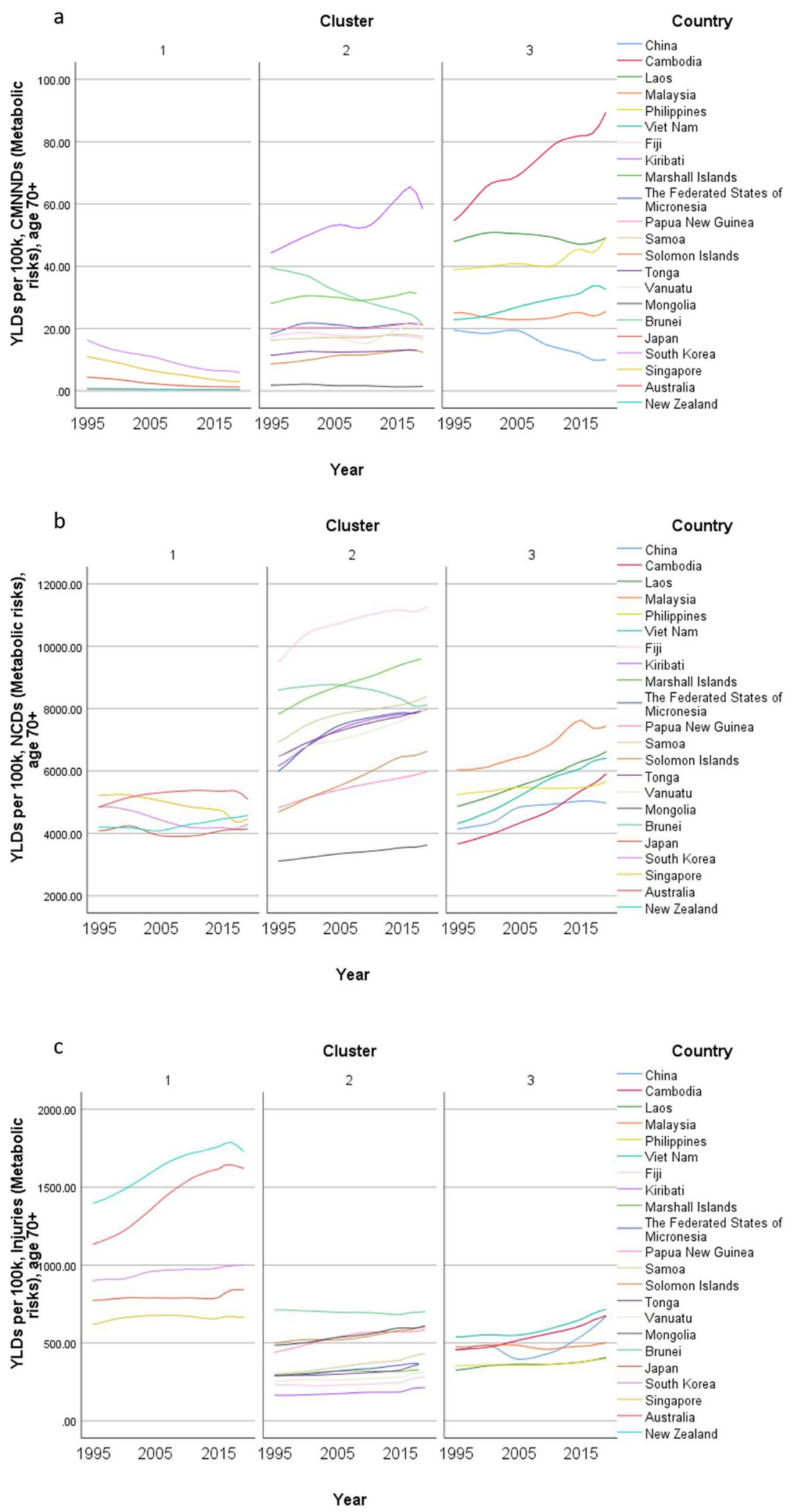
Fig. 2 (continued)

d
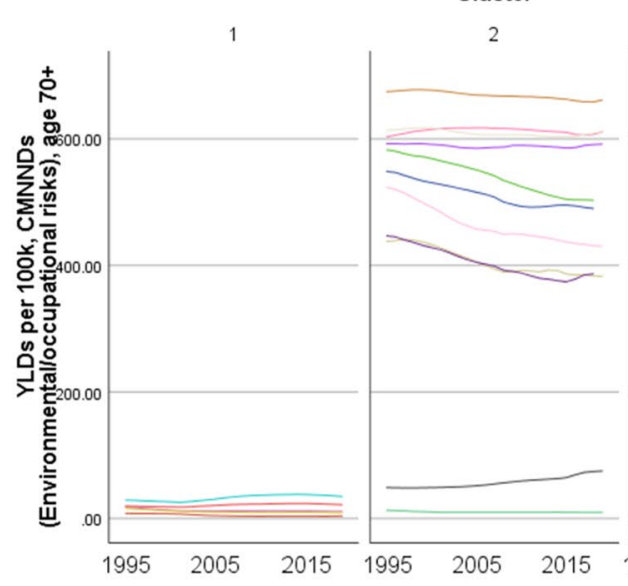

Year

e

Cluster

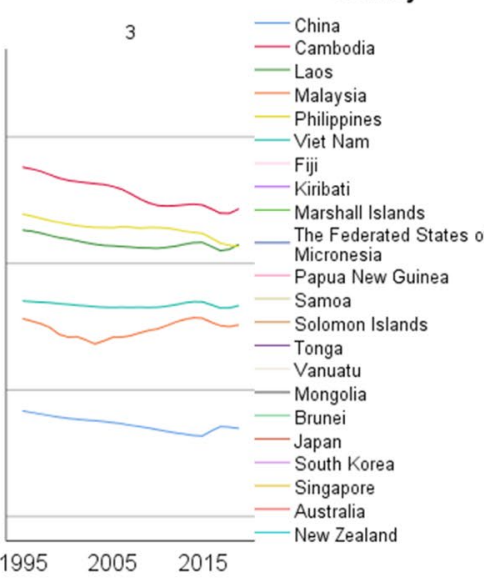

2
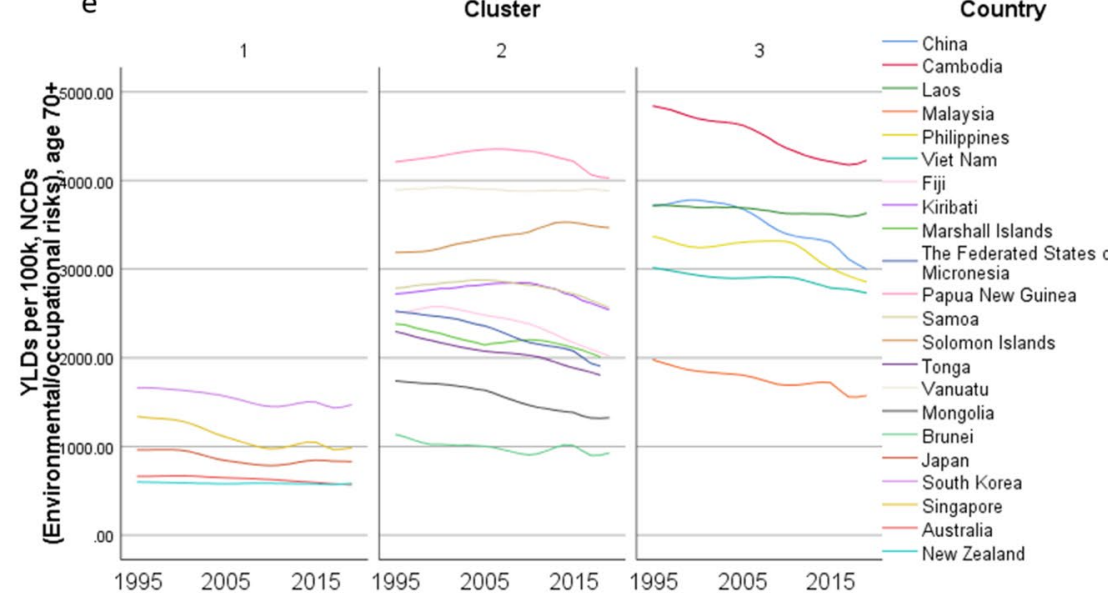

Year

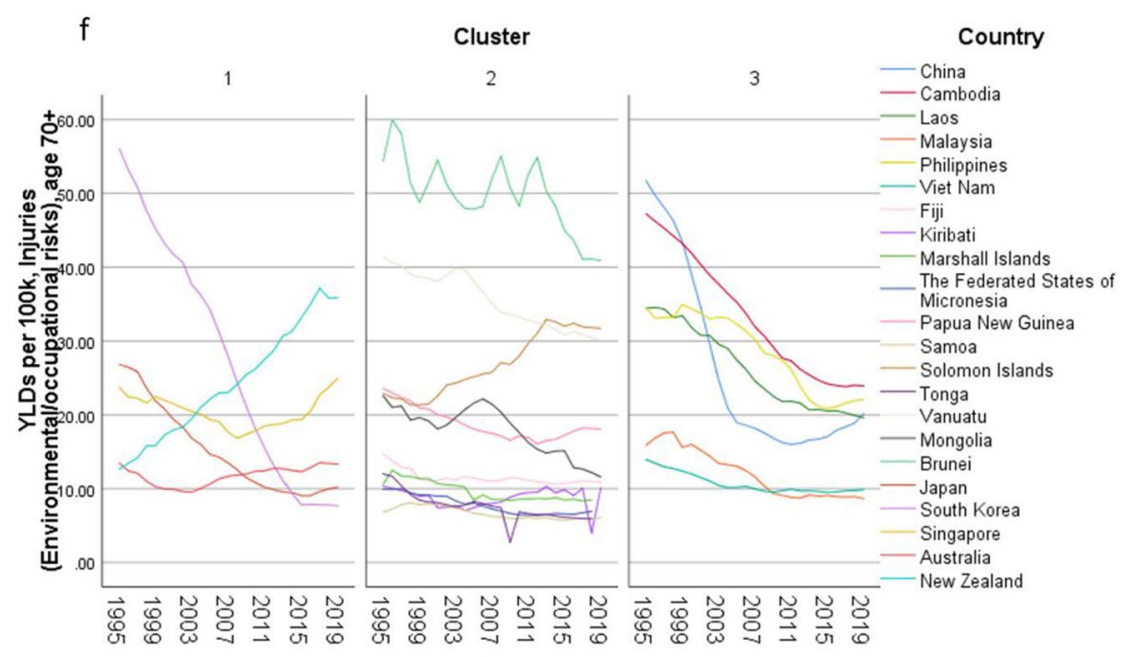


Fig. 2 (continued)

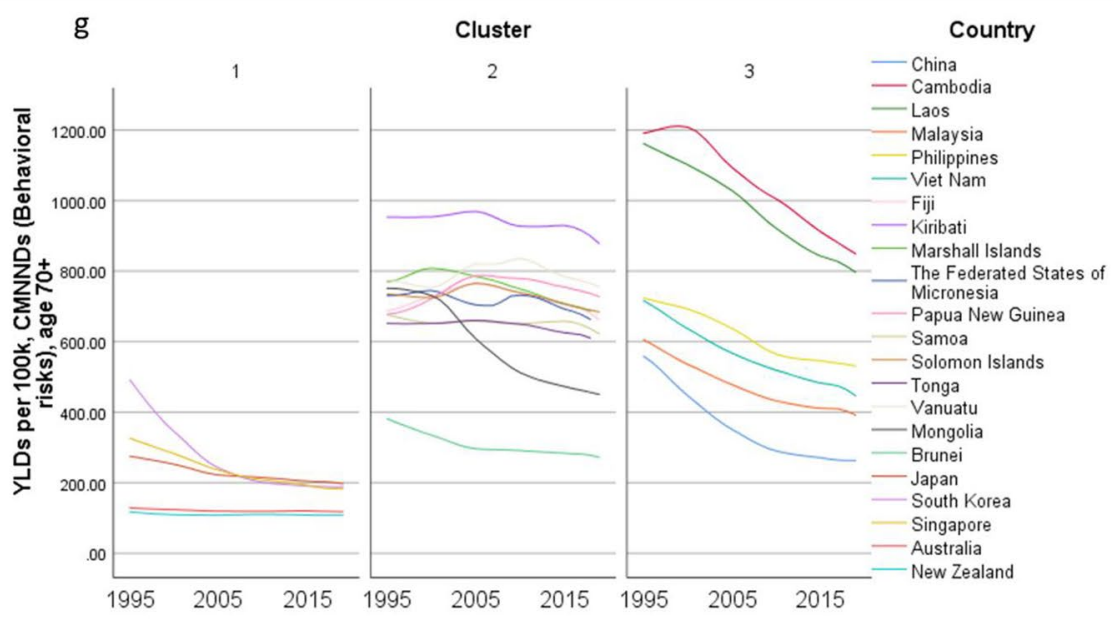

Year

h

Cluster

Country

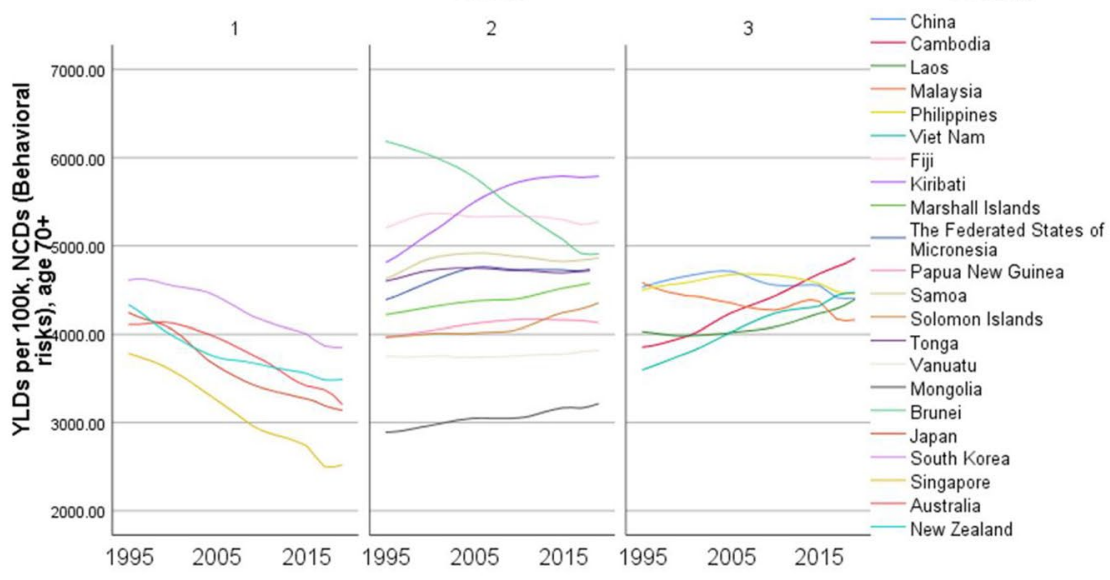

Year

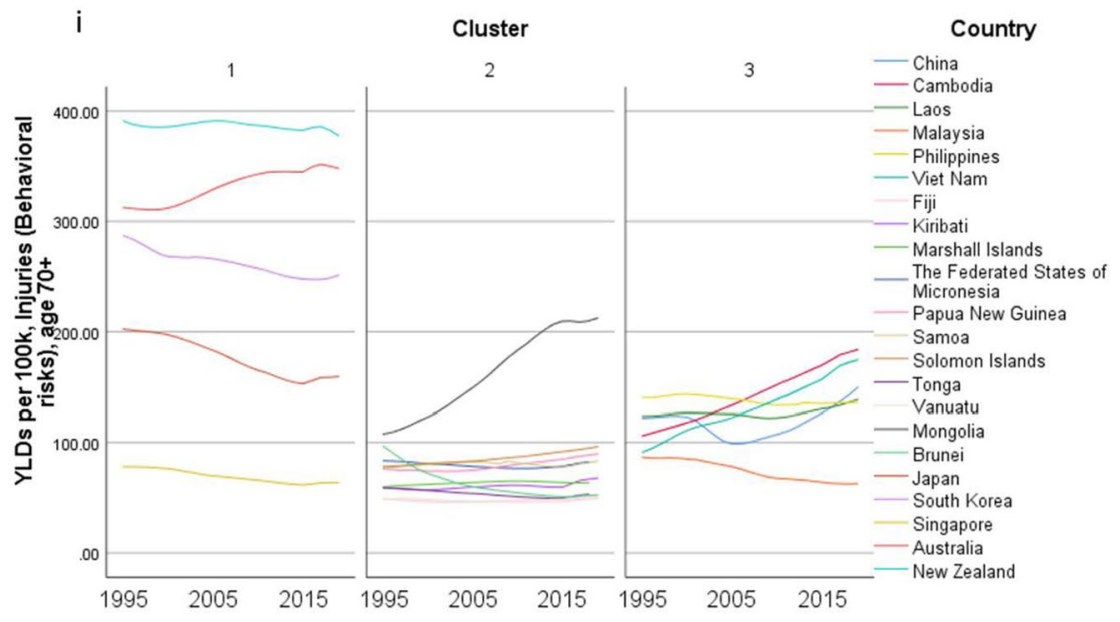

Year 
Fig. 3 Graphs of mortality rate (per $100 \mathrm{~K}$ ) over time by clusters, 1995-2019. [Metabolic risks = i.e., high fasting plasma glucose; high cholesterol; high blood pressure; high BMI; low bone mineral density; impaired kidney function. Environmental / Occupational risks = i.e., unsafe water; sanitation; handwashing; air pollution; exposure to occupational carcinogens. Behavioural risks $=$ i.e. child \& maternal malnutrition; tobacco use; alcohol use; drug use; dietary risks; intimate partner violence; childhood maltreatment; unsafe sex; low physical activity. $C M N N D=$ communica ble, maternal, neonatal and nutritional diseases. $N C D=$ non-communicable disease]
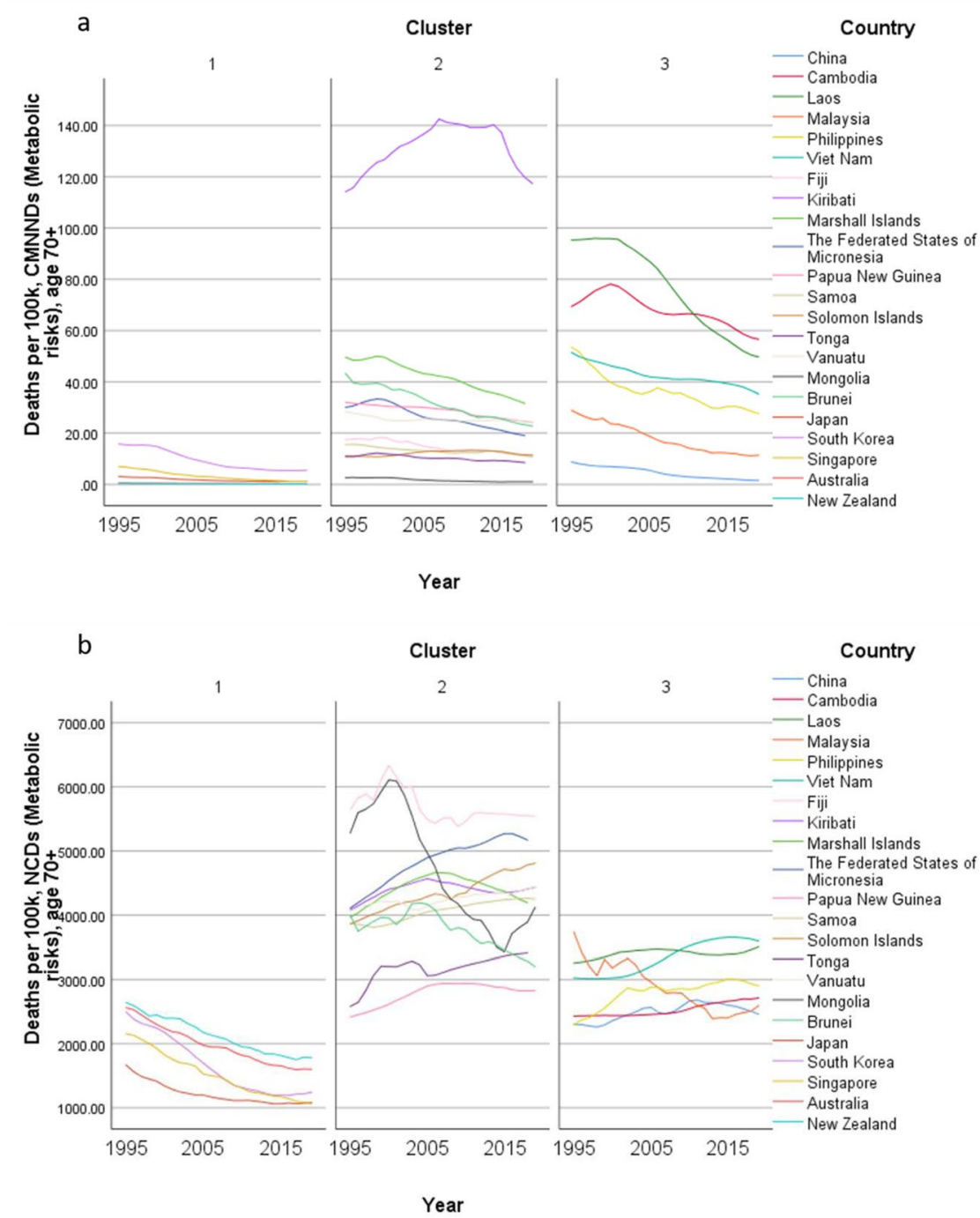

C

Cluster

2

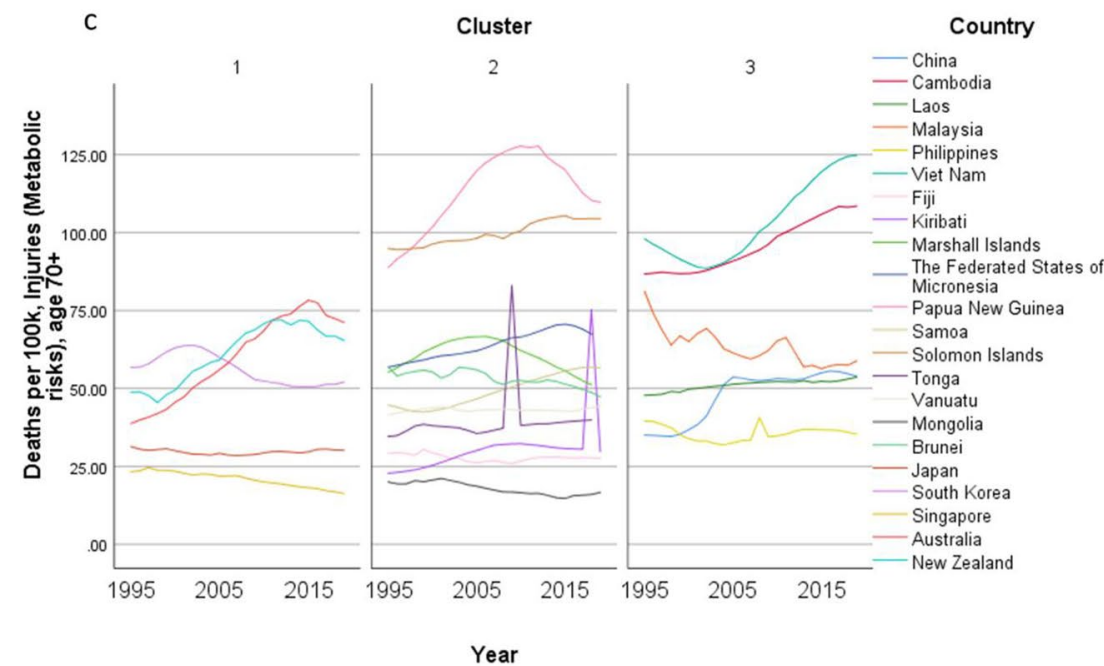

Country 
Fig. 3 (continued)
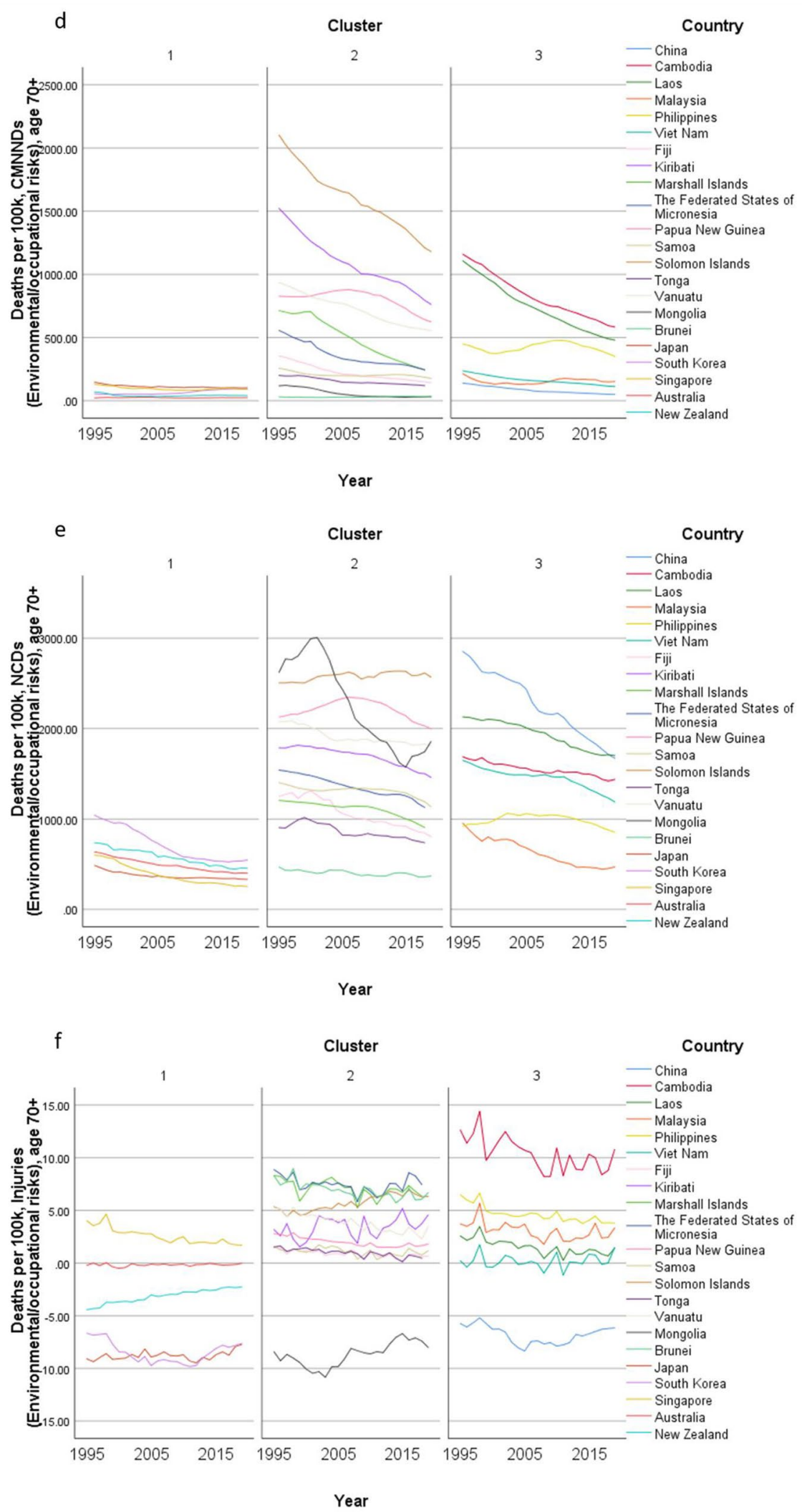
Fig. 3 (continued)
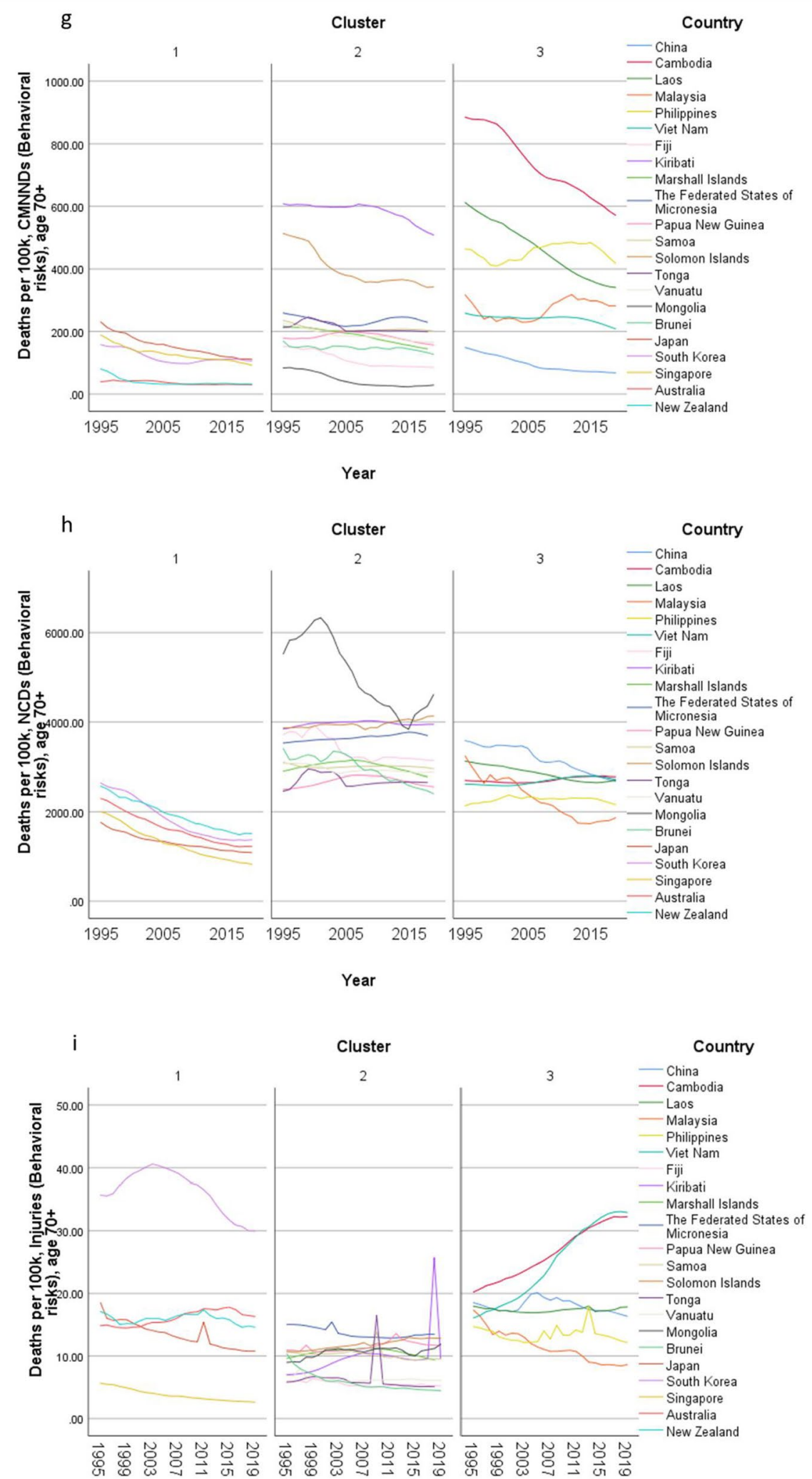
Table 3 Correlations between sociodemographic factors, health spending, and YLD rates (per $100 \mathrm{~K}$ ) of risk-cause pairs in adults $70+$ years old, in the pooled sample

\begin{tabular}{|c|c|c|c|c|c|c|c|c|c|}
\hline & $\begin{array}{l}\text { Met, } \\
\text { CMNND }\end{array}$ & $\begin{array}{l}\text { Met, } \\
\text { NCD }\end{array}$ & $\begin{array}{l}\text { Met, } \\
\text { Inj }\end{array}$ & $\begin{array}{l}\text { Env/Occ, } \\
\text { CMNND }\end{array}$ & $\begin{array}{l}\text { Env/Occ, } \\
\text { NCD }\end{array}$ & $\begin{array}{l}\text { Env/Occ, } \\
\text { Inj }\end{array}$ & $\begin{array}{l}\text { Beh, } \\
\text { CMNND }\end{array}$ & $\begin{array}{l}\text { Beh, } \\
\text { NCD }\end{array}$ & $\begin{array}{l}\text { Beh, } \\
\text { Inj }\end{array}$ \\
\hline Sociodemographic index (SDI) & $-0 \cdot 581 * *$ & $-0 \cdot 061 *$ & $0 \cdot 503^{*} *$ & $-0 \cdot 815 * *$ & $-0 \cdot 866^{* *}$ & $-0 \cdot 197 * *$ & $-0 \cdot 718 * *$ & $-0 \cdot 110 * *$ & $0 \cdot 168 * *$ \\
\hline HAQI frontier & $-0 \cdot 590 * *$ & $-0 \cdot 018$ & $0.526 * *$ & $-0 \cdot 799 * *$ & $-0 \cdot 893 * *$ & $-0 \cdot 162 * *$ & $-0 \cdot 707 * *$ & $-0 \cdot 122 * *$ & $0 \cdot 157 * *$ \\
\hline GDP per capita in PPP & $-0 \cdot 495 * *$ & $-0 \cdot 127 * *$ & $0.593 * *$ & $-0 \cdot 856 * *$ & $-0 \cdot 781 * *$ & $-0 \cdot 055$ & $-0 \cdot 703 * *$ & $-0 \cdot 085 * *$ & $0 \cdot 243 * *$ \\
\hline $\begin{array}{l}\text { Mean years of education, age } \\
25-29\end{array}$ & $-0.549 * *$ & $0 \cdot 028$ & $0 \cdot 364 * *$ & $-0.648 * *$ & $-0 \cdot 808 * *$ & $-0 \cdot 271 * *$ & $-0 \cdot 640 * *$ & $-0 \cdot 087 * *$ & $0 \cdot 140 * *$ \\
\hline Fertility per 1000 , age $10-24$ & $0 \cdot 362 * *$ & $0 \cdot 150 * *$ & $-0 \cdot 500 * *$ & $0 \cdot 808 * *$ & $0 \cdot 629 * *$ & $0 \cdot 185^{* *}$ & $0 \cdot 622 * *$ & $0 \cdot 040$ & $-0 \cdot 187 * *$ \\
\hline $\begin{array}{l}\text { Total health spending per capita } \\
\text { in PPP }\end{array}$ & $-0 \cdot 522 * *$ & $-0 \cdot 082 * *$ & $0.529 * *$ & $-0.783 * *$ & $-0 \cdot 874 * *$ & $-0 \cdot 190 * *$ & $-0 \cdot 691 * *$ & $-0 \cdot 111 * *$ & $0 \cdot 201 * *$ \\
\hline Total health spending per GDP & $-0 \cdot 097 * *$ & $-0 \cdot 167 * *$ & $0 \cdot 092 * *$ & $-0 \cdot 040$ & $-0 \cdot 113 * *$ & $-0 \cdot 200 * *$ & $-0 \cdot 112 * *$ & 0.0028 & $0 \cdot 230 * *$ \\
\hline Government spending per THS & $-0 \cdot 437 * *$ & $0 \cdot 206^{* *}$ & $0 \cdot 077 * *$ & $-0 \cdot 117 * *$ & $-0 \cdot 424 * *$ & $-0.093 * *$ & $-0 \cdot 276^{* *}$ & $0 \cdot 051$ & $-0 \cdot 067 *$ \\
\hline $\begin{array}{l}\text { Prepaid private spending per } \\
\text { THS }\end{array}$ & $-0 \cdot 183 * *$ & $-0 \cdot 231 * *$ & $0 \cdot 244 * *$ & $-0 \cdot 440 * *$ & $-0 \cdot 288 * *$ & $-0 \cdot 053$ & $-0 \cdot 286^{* *} *$ & $-0 \cdot 159 * *$ & $0 \cdot 165^{* *}$ \\
\hline $\begin{array}{l}\text { Out-of-pocket spending per } \\
\text { THS }\end{array}$ & $0 \cdot 271 * *$ & $-0 \cdot 313 * *$ & $0 \cdot 144 * *$ & $-0 \cdot 270 * *$ & $0.071 *$ & $0 \cdot 054$ & $0 \cdot 035$ & $-0 \cdot 070 *$ & $0 \cdot 185^{* *}$ \\
\hline
\end{tabular}

$* p<0 \cdot 05, * * p<0 \cdot 01$. YLD: years lived with disability. HAQI frontier: healthcare access and quality index computed based on relationship between HAQI and SDI. GDP: gross domestic product. PPP: purchasing power parity. THS: total health spending. Met: metabolic risks (i.e. high fasting plasma glucose; high cholesterol; high blood pressure; high BMI; low bone mineral density; impaired kidney function). Env/Occ: environmental/occupational risks (i.e., unsafe water; sanitation; handwashing; air pollution; exposure to occupational carcinogens). Beh: behavioral risks (i.e., child \& maternal malnutrition; tobacco use; alcohol use; drug use; dietary risks; intimate partner violence; childhood maltreatment; unsafe sex; low physical activity). CMNND: communicable, maternal, neonatal and nutritional diseases. NCD: non-communicable disease. Inj: injuries

environmental/ occupational risks were much weaker than other correlations. As for mortality, the rates of CMNNDs, NCDs as well as injuries attributable to environmental/ occupational risks had stronger correlations with LE, HALE, and LHE at $70+$ than other rates. In comparison, injuries related to metabolic risks and behavior risks had weaker associations with the life expectancy parameters. It was interesting to see that there were generally low correlations between YLD and mortality with the ratio of health spending to GDP or total health spending, such as THS per GDP, government spending per THS, and private spending per THS. Lower SDI, HAQI, GDP or THS per person were associated with higher death rates of NCD ascribed to metabolic risks as well as behavioral risks.

\section{Correlation matrix}

In relation to specific disease groups, among all correlations with life expectancy or HALE, only the correlation between HALE and YLDs attributable to neurological disorder and behavioral risks in 1995 were non-significant $(\mathrm{rho}=0.01, p=0.25)$. All other correlations were significant $(p<0.05)$. As shown in Fig. 4, the correlations between life expectancy and deaths from CVD, CRD, DM and renal diseases were strong, and their correlations with SDI became stronger in 2019 compared with 1995.

Concerning YLDs, in 1995, HALE showed moderate to weak correlations with YLDs (Fig. 5). However, in 2019, the correlations between HALE and YLDs from CVD, musculoskeletal disorders, sense organ diseases, and diabetes and renal diseases became stronger. Noticeably, the correlations between HALE and digestive diseases due to metabolic risk, as well as mental health disorders due to environmental /occupational risks, also became stronger. Overall, the correlation between SDI and CVD and sense organ diseases became stronger, although the correlation between SDI and CRD became weaker. The correlation between SDI and cancer due to metabolic risk and behavioral risk, as well as digestive diseases due to metabolic risk, were stronger over time. Moreover, the correlation between SDI and musculoskeletal 
Table 4 Correlations between sociodemographic factors, health spending, and mortality rates (per $100 \mathrm{~K}$ ) of risk-cause pairs in adults $70+$ years old, in the pooled sample

\begin{tabular}{|c|c|c|c|c|c|c|c|c|c|}
\hline & $\begin{array}{l}\text { Met, } \\
\text { CMNND }\end{array}$ & $\begin{array}{l}\text { Met, } \\
\text { NCD }\end{array}$ & $\begin{array}{l}\text { Met, } \\
\text { Inj }\end{array}$ & $\begin{array}{l}\text { Env/Occ, } \\
\text { CMNND }\end{array}$ & $\begin{array}{l}\text { Env/Occ, } \\
\text { NCD }\end{array}$ & $\begin{array}{l}\text { Env/Occ, } \\
\text { Inj }\end{array}$ & $\begin{array}{l}\text { Beh, } \\
\text { CMNND }\end{array}$ & $\begin{array}{l}\text { Beh, } \\
\text { NCD }\end{array}$ & $\begin{array}{l}\text { Beh, } \\
\text { Inj }\end{array}$ \\
\hline Sociodemographic index (SDI) & $-0.698 * *$ & $-0 \cdot 579 * *$ & $-0 \cdot 173 * *$ & $-0 \cdot 830 * *$ & $-0 \cdot 834 * *$ & $-0 \cdot 396 * *$ & $-0 \cdot 567 * *$ & $-0 \cdot 548 * *$ & $-0.089 * *$ \\
\hline HAQI frontier & $-0.696 * *$ & $-0 \cdot 501 * *$ & $-0 \cdot 146^{* *}$ & $-0.871 * *$ & $-0.835 * *$ & $-0 \cdot 325 * *$ & $-0 \cdot 609 * *$ & $-0 \cdot 508 * *$ & $-0 \cdot 113 * *$ \\
\hline GDP per capita in PPP & $-0 \cdot 617 * *$ & $-0.489 * *$ & $-0 \cdot 131 * *$ & $-0 \cdot 846 * *$ & $-0 \cdot 779 * *$ & $-0 \cdot 377 * *$ & $-0 \cdot 568 * *$ & $-0 \cdot 469 * *$ & $-0 \cdot 063^{*}$ \\
\hline $\begin{array}{l}\text { Mean years of education, age } \\
25-29\end{array}$ & $-0 \cdot 650 * *$ & $-0.497 * *$ & $-0 \cdot 184 * *$ & $-0 \cdot 729 * *$ & $-0 \cdot 796 * *$ & $-0 \cdot 350 * *$ & $-0 \cdot 520 * *$ & $-0 \cdot 519 * *$ & $-0 \cdot 088 * *$ \\
\hline Fertility per 1000 , age $10-24$ & $0 \cdot 509 * *$ & $0 \cdot 574 * *$ & $0 \cdot 024$ & $0 \cdot 655^{* *}$ & $0.606 * *$ & $0 \cdot 450 * *$ & $0 \cdot 378 * *$ & $0.441 * *$ & $-0 \cdot 023$ \\
\hline $\begin{array}{l}\text { Total health spending per capita } \\
\text { in PPP }\end{array}$ & $-0 \cdot 643 * *$ & $-0 \cdot 551 * *$ & $-0 \cdot 126^{* *}$ & $-0.796 * *$ & $-0.799 * *$ & $-0.334 * *$ & $-0.534 * *$ & $-0.506 * *$ & $-0 \cdot 057 *$ \\
\hline Total health spending per GDP & $-0 \cdot 114 * *$ & $-0 \cdot 092 * *$ & $0 \cdot 104 * *$ & $0.056^{*}$ & $-0 \cdot 0013$ & $-0 \cdot 180 * *$ & $0 \cdot 036$ & $-0 \cdot 040$ & $0 \cdot 189 * *$ \\
\hline Government spending per THS & $-0 \cdot 349 * *$ & $0 \cdot 118 * *$ & $-0 \cdot 142 * *$ & $-0 \cdot 273 * *$ & $-0 \cdot 264 * *$ & $-0 \cdot 075^{*} *$ & $-0 \cdot 272 * *$ & $0 \cdot 0012$ & $-0 \cdot 161 * *$ \\
\hline $\begin{array}{l}\text { Prepaid private spending per } \\
\text { THS }\end{array}$ & $-0 \cdot 303 * *$ & $-0 \cdot 434 * *$ & $-0 \cdot 090 * *$ & $-0 \cdot 338 * *$ & $-0 \cdot 328 * *$ & $-0 \cdot 313 * *$ & $-0 \cdot 302 * *$ & $-0.378 * *$ & $0 \cdot 036$ \\
\hline $\begin{array}{l}\text { Out-of-pocket spending per } \\
\text { THS }\end{array}$ & $0 \cdot 102 * *$ & $-0 \cdot 404 * *$ & $0 \cdot 030$ & $-0 \cdot 132 * *$ & $-0 \cdot 084 * *$ & $-0 \cdot 106 * *$ & $0.055^{*}$ & $-0 \cdot 214 * *$ & $0 \cdot 153 * *$ \\
\hline
\end{tabular}

${ }^{*} p<0 \cdot 05, * * p<0 \cdot 01$. HAQI frontier: healthcare access and quality index computed based on relationship between HAQI and SDI. GDP: gross domestic product. PPP: purchasing power parity. THS: total health spending. Met: metabolic risks (i.e., high fasting plasma glucose; high cholesterol; high blood pressure; high BMI; low bone mineral density; impaired kidney function). Env/Occ: environmental/occupational risks (i.e., unsafe water; sanitation; handwashing; air pollution; exposure to occupational carcinogens). Beh: behavioral risks (i.e., child \& maternal malnutrition; tobacco use; alcohol use; drug use; dietary risks; intimate partner violence; childhood maltreatment; unsafe sex; low physical activity). CMNND: communicable, maternal, neonatal and nutritional diseases. NCD: non-communicable disease. Inj: injuries

disorders, DM and renal disease, and mental health disorders due to environmental/ occupational risk became stronger in 2019 too.

\section{Regression analyses}

In the linear mixed effects regression analyses, SDI was the most significant independent variable of all-risk and all-cause YLD rate and mortality rate (Tables 6, 7). Higher SDI was associated with around 1600 years decrease in YLDs per $100 \mathrm{~K}$ of population and a drop in nearly 1500 deaths per $100 \mathrm{~K}$ of population, when health spending was adjusted for (Model I). When HAQI was controlled for in the models (Model II), health spending was associated with almost 240 less YLDs per $100 \mathrm{~K}$ and around 150 less deaths per $100 \mathrm{~K}$ for those at $70+$ years old. The mortality rate in females was significantly lower than males by around 1200 deaths per $100 \mathrm{~K}$ of population. One unit of THS per capita was associated with a fall in more than 150 deaths per $100 \mathrm{~K}$ of population (model II).
When generalised additive mixture modelling was applied, it was shown that between 1995 and 2019, the change in LHE at 70+ was minimal (Table 8). Overall, YLD rates of CMNNDs attributable to level 1 (metabolic) risks were associated with a lower LHE when other YLD rates were adjusted for. For example, one YLD per $100 \mathrm{~K}$ of population related to behavioral risk was associated with a decrease in LHE by 0.2 years. One YLD per $100 \mathrm{~K}$ of population due to metabolic risk was correlated with a 4-month less of LHE. However, YLD rates of NCDs and injuries attributable to metabolic risks were associated with a rise in LHE. One YLD per $100 \mathrm{~K}$ of population related to $\mathrm{NCD}$ or injuries was associated with 0.25 or 0.2 years more in LHE. YLD rate of NCD associated with behavioral risks was correlated with a fall in LHE, but the result was only significant in the non-linear relationship. YLD rate of injuries attributable to environmental/occupational risks was associated with longer LHE.

The change in life expectancy was non-significant when mortality rates were controlled for between 1995 and 2019 (Table 9). Overall, the death rates of NCDs were associated with lower life expectancy. The 
Table 5 Correlations between YLD rates and mortality rates (per $100 \mathrm{~K}$ ) of risk-cause pairs and the life expectancy and LHE fraction at $70+$ years old, in the pooled sample

\begin{tabular}{|c|c|c|c|c|}
\hline & LE at $70+$ & HALE at $70+$ & LHE at $70+$ & LHE fraction at $70+$ \\
\hline YLD (Met, CMNND) & $-0 \cdot 494 * *$ & $-0 \cdot 492 * *$ & $-0.478 * *$ & $-0.071 * *$ \\
\hline YLD (Met, NCD) & $-0 \cdot 235^{* *}$ & $-0 \cdot 300 * *$ & $-0 \cdot 097 * *$ & $0.470 * *$ \\
\hline YLD (Met, Inj) & $0 \cdot 528 * *$ & $0 \cdot 494 * *$ & $0 \cdot 562 * *$ & $0 \cdot 288 * *$ \\
\hline YLD (Env/Occ, CMNND) & $-0 \cdot 644 * *$ & $-0.675 * *$ & $-0 \cdot 565^{* *}$ & $0 \cdot 109 * *$ \\
\hline YLD (Env/Occ, NCD) & $-0 \cdot 455^{* *}$ & $-0 \cdot 434 * *$ & $-0 \cdot 472 * *$ & $-0 \cdot 178 * *$ \\
\hline YLD (Env/Occ, Inj) & $-0 \cdot 340 * *$ & $-0 \cdot 275 * *$ & $-0 \cdot 452 * *$ & $-0 \cdot 553 * *$ \\
\hline YLD (Beh, CMNND) & $-0 \cdot 377 * *$ & $-0 \cdot 422 * *$ & $-0 \cdot 270 * *$ & $0 \cdot 315^{* *}$ \\
\hline YLD (Beh, NCD) & $-0 \cdot 448 * *$ & $-0 \cdot 417 * *$ & $-0.487 * *$ & $-0 \cdot 246 * *$ \\
\hline YLD (Beh, Inj) & $0 \cdot 028$ & $0 \cdot 080 * *$ & $-0 \cdot 077 * *$ & $-0 \cdot 369 * *$ \\
\hline Mortality (Met, CMNND) & $-0 \cdot 619 * *$ & $-0 \cdot 609 * *$ & $-0 \cdot 612 * *$ & $-0 \cdot 159 * *$ \\
\hline Mortality (Met, NCD) & $-0 \cdot 788 * *$ & $-0 \cdot 812 * *$ & $-0 \cdot 699 * *$ & $0 \cdot 099 * *$ \\
\hline Mortality (Met, Inj) & $-0 \cdot 064 *$ & $-0 \cdot 123 * *$ & $0 \cdot 046$ & $0 \cdot 456^{* *}$ \\
\hline Mortality (Env/Occ, CMNND) & $-0 \cdot 552 * *$ & $-0 \cdot 572 * *$ & $-0 \cdot 501 * *$ & $-0 \cdot 0055$ \\
\hline Mortality (Env/Occ, NCD) & $-0 \cdot 615^{* *}$ & $-0 \cdot 569 * *$ & $-0 \cdot 671 * *$ & $-0 \cdot 374 * *$ \\
\hline Mortality (Env/Occ, Inj) & $-0 \cdot 518 * *$ & $-0 \cdot 524 * *$ & $-0 \cdot 491 * *$ & $-0 \cdot 063 *$ \\
\hline Mortality (Beh, CMNND) & $-0 \cdot 549 * *$ & $-0 \cdot 524 * *$ & $-0 \cdot 585 * *$ & $-0 \cdot 308 * *$ \\
\hline Mortality (Beh, NCD) & $-0 \cdot 877 * *$ & $-0 \cdot 828 * *$ & $-0 \cdot 921 * *$ & $-0 \cdot 421 * *$ \\
\hline Mortality (Beh, Inj) & $-0 \cdot 245^{* *}$ & $-0 \cdot 184 * *$ & $-0 \cdot 355^{* *}$ & $-0 \cdot 491 * *$ \\
\hline
\end{tabular}

${ }^{*} p<0 \cdot 05, * * p<0 \cdot 01$. YLD: years lived with disability. LE: life expectancy. HALE: healthy life expectancy. LHE: equivalent years of healthy life lost. Met: metabolic risks (i.e., high fasting plasma glucose; high cholesterol; high blood pressure; high BMI; low bone mineral density; impaired kidney function). Env/Occ: environmental/occupational risks (i.e., unsafe water; sanitation; handwashing; air pollution; exposure to occupational carcinogens). Beh: behavioral risks (i.e., child \& maternal malnutrition; tobacco use; alcohol use; drug use; dietary risks; intimate partner violence; childhood maltreatment; unsafe sex; low physical activity). CMNND: communicable, maternal, neonatal and nutritional diseases. NCD: non-communicable disease. Inj: injuries

mortality rates of NCDs with respect to behavioral risks and metabolic risks were associated with 1.9 and 0.4 years decrease in life expectancy respectively. The mortality of CMNNDs attributable to environmental/ occupational risks and behavioral risks were associated with around 0.8 and 0.1 years decrease in life expectancy respectively. In addition, the death rate of injuries attributable to metabolic risks and behavioral risks were associated with shorter life expectancy when other risk related mortality rates were adjusted for.

\section{Discussion}

A key finding in this study on older adults over the age of 70 years in the Western Pacific Region is the categorisation of 22 countries into three clusters, which can have implications for regional policy planning, for example by the World Health Organization. Life expectancy and HALE at $70+$ increased steadily over the years, which is more evident in developed countries and also with some upward trends in developing countries. It creates an urgency for health planning to focus on factors affecting health outcomes in older adults across the region. Other important messages from this study include that SDI is the most significant factor to both YLD rate and mortality rate. Health system indicators such as health spending was not consistently linked with disease burden on older adults when SDI and HAQI were taken into account. The results suggested that the overall sociodemographic development could be an important determinant of health outcomes beyond health spending and healthcare access and quality. Hence, integrated health planning strategies are needed. YLDs and mortality from NCDs, while being key issues in all three clusters, increased considerably in the developing countries. Wide variations in health risks were also observed in the Western Pacific countries, but no major change was, however, shown from 1995 to 

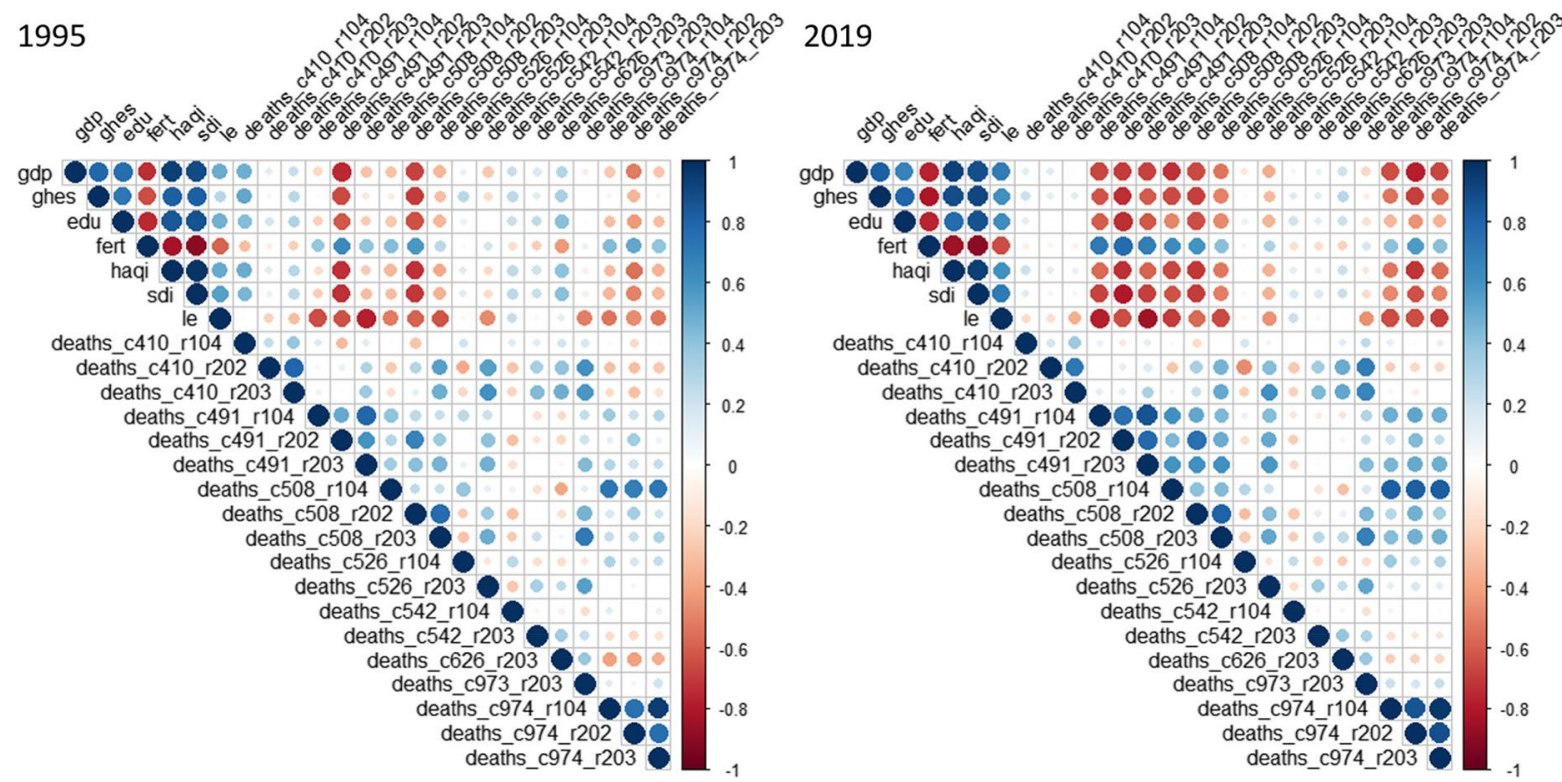

gdp: GDP per capita, computed by dividing THE per capita by THE per GDP. ghes: government health expenditure as source, in PPP per capita . edu: mean years of schooling, at age group 25-29. fert: total fertility under 25 years (TFU25), age 10-24. haqi: HAQI frontier with missing data replaced with linear trend. sdi: sociodemographic index. le: life expectancy, mean value of five age groups from 70-74 to 90-94. hale: healthy life expectancy, mean value of five age groups from 70-74 to 90-94. deaths: number of deaths, per 100K. c: cause. r: risk. 410: neoplasms. 491: CVD. 508: chronic respiratory diseases. 526: digestive disease . 542: neurological disorders. 558: mental disorders. 626: musculoskeletal disorders. 669: sense organ diseases. 973: substance use disorders. 974: diabetes and kidney diseases . 104: metabolic risks. 202: environmental risks/occupational risks. 203: behavioural risks.

Fig. 4 Correlation matrix of sociodemographic variables, life expectancy, and death rates in 1995 and 2019

2019 for many of such risks. In addition, women had better YLDs rates and mortality outcomes than men.

The findings in the current study in part are consistent with the results from the previous GBD studies. Additionally, the results provided insights into the associations between sociodemographic factors, disease burden, and life expectancy as well as the proportion of years spent in poor health among older adults in the Western Pacific countries, which has not been done before. This study found that though developed countries (cluster 1) had higher total health spending (THS) per capita and lower YLD rate and mortality rate than developing countries (cluster 2 and 3), THS per person was not the most significant factor to disease burden when SDI was adjusted for. Also, the gap in YLDs rate between developing countries and developed countries has been growing wider along with healthy life expectancy. The developing countries should particularly be the targets of assistance in international public health interventions.
The sociodemographic index was found to be a more important factor to YLD rate and mortality rate than THS per capita in the current study. As high SDI reflects higher GDP and education years and lower fertility rates, it may be a relatively distal proxy compared with other factors such as the availability and accessibility [31], quality [32] and error in diagnostic tests and treatments [33] which could have differential impact on the YLD and mortality between countries. Further global study of country-specific estimates with respect to proximal, focused, and modifiable factors to disease burden is required. There is limited work in interventions to improve socioeconomic status as a driver to health outcomes in the ageing population. However, work in other age groups or conditions suggest that structural interventions (see examples in: https://www.who.int/social_determinan ts/knowledge_networks/phconditions/structural_inter ventions.pdf) may improve health inequalities and outcomes [34-36]. 

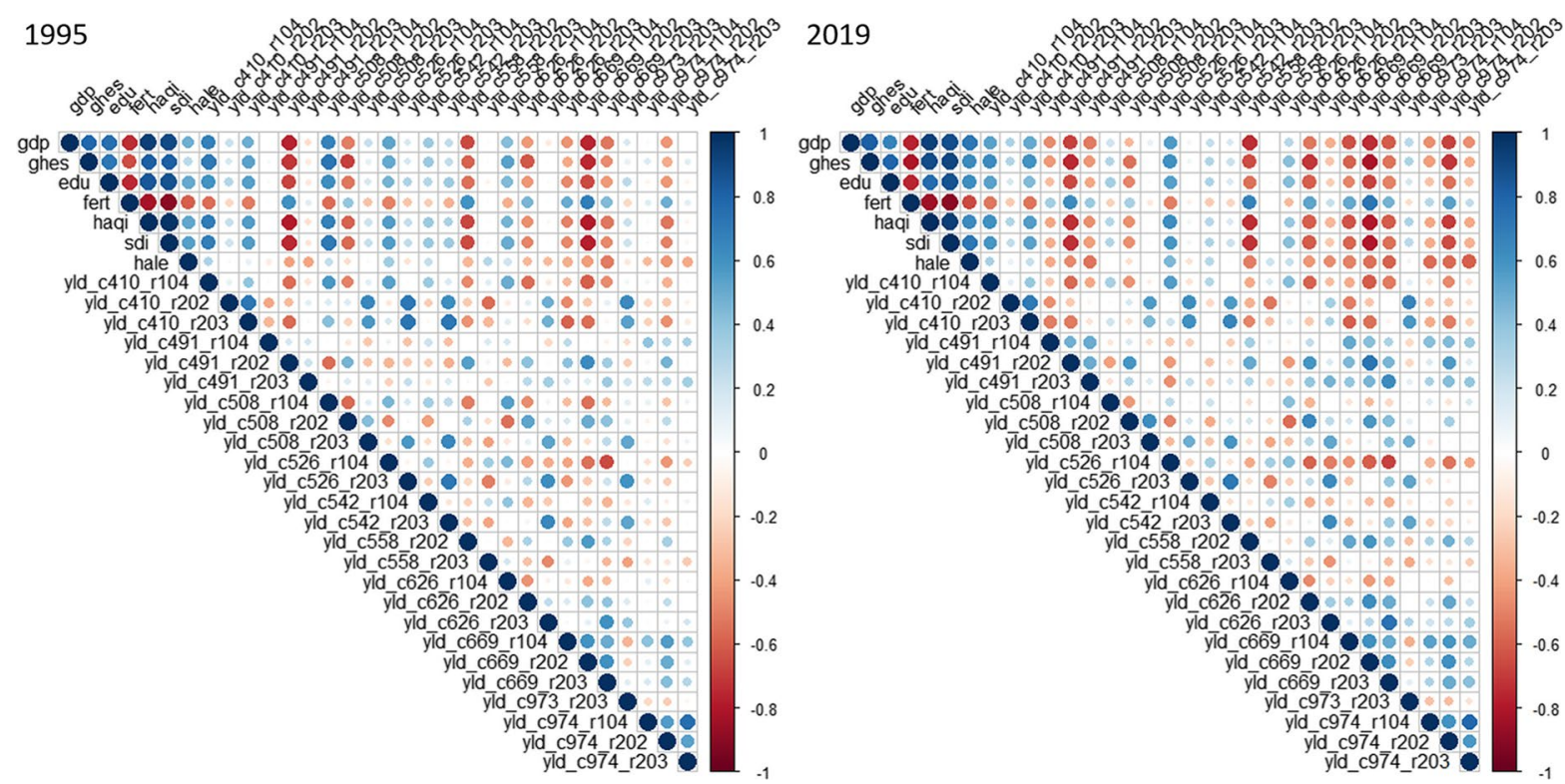

gdp: GDP per capita, computed by dividing THE per capita by THE per GDP. ghes: government health expenditure as source, in PPP per capita . edu: mean years of schooling, at age group 25-29. fert: total fertility under 25 years (TFU25), age 10-24. haqi: HAQI frontier with missing data replaced with linear trend. sdi: sociodemographic index. le: life expectancy, mean value of five age groups from 70-74 to 90-94. hale: healthy life expectancy, mean value of five age groups from 70-74 to 90-94. yld: years lived with disability, per 100K. c: cause. r: risk. 410: neoplasms. 491: CVD. 508: chronic respiratory diseases. 526: digestive disease . 542: neurological disorders. 558: mental disorders. 626: musculoskeletal disorders. 669: sense organ diseases. 973: substance use disorders. 974: diabetes and kidney diseases . 104: metabolic risks. 202: environmental risks/ occupational risks. 203: behavioural risks.

Fig. 5 Correlation matrix of sociodemographic variables, HALE, and YLDs rates in 1995 and 2019

The risks attributable to NCDs were the major contributors to the disease burden for those aged 70 years or above in the Western Pacific Region by 2019. For example, the YLD rates of diabetes related to hyperglycaemia, ischemic stroke attributable to hypertension, and COPD associated with smoking were the highest among all risk-cause pairs in the literature [37]. The mortality rates of ischemic heart disease associated with hypertension and hypercholesterolemia, as well as cancers related to smoking, were the top-ranked rates in older adults [37].

In terms of country risk profiles, a number of factors are proposed to be associated with an increased risk of NCDs in these countries. With respect to

Table 6 Linear mixed effect models to assess YLD rates (per $100 \mathrm{~K}$ ) with respect to sociodemographic factors and health spending

\begin{tabular}{|c|c|c|c|c|}
\hline & Estimate & $95 \% \mathrm{CI}$ & $t(d f)$ & $F($ edf) \\
\hline Intercept & $11,560 \cdot 1$ & {$[10190 \cdot 82,12,929 \cdot 37]$} & $16 \cdot 55(1294) * * *$ & \\
\hline Sex & $-528 \cdot 35$ & {$[-1394 \cdot 26,337 \cdot 57]$} & $-1 \cdot 2(1294)$ & \\
\hline Year & $386 \cdot 09$ & {$[311 \cdot 11,461 \cdot 06]$} & $10 \cdot 09(1294) * * *$ & $25.98(7.47)^{* * *}$ \\
\hline SDI & $-1514 \cdot 41$ & {$[-1934 \cdot 03,-1094 \cdot 79]$} & $-7 \cdot 07(1294) * * *$ & $30 \cdot 48(8 \cdot 36)^{* * *}$ \\
\hline HAQI frontier & $-105 \cdot 15$ & {$[-251 \cdot 89,41 \cdot 6]$} & $-1.4(1294)$ & $1.34(3.63)$ \\
\hline THS per capita & $11 \cdot 15$ & {$[-45 \cdot 45,67 \cdot 74]$} & $0 \cdot 39(1294)$ & $0 \cdot 15(1)$ \\
\hline
\end{tabular}

Adjusted $R$ squared $=0 \cdot 26$. $* p<0 \cdot 05, * * p<0 \cdot 01, * * * p<0 \cdot 001$. YLD: years lived with disability. SDI: socio-demographic index. HAQI frontier: healthcare access and quality index computed based on relationship between HAQI and SDI. THS: total health spending 
Table 7 Linear mixed effect models to assess mortality rates (per $100 \mathrm{~K}$ ) with respect to sociodemographic factors and health spending

\begin{tabular}{|c|c|c|c|c|}
\hline & Estimate & $95 \% \mathrm{CI}$ & $t(d f)$ & $\mathrm{F}$ (edf) \\
\hline Intercept & $7105 \cdot 22$ & {$[6256 \cdot 52,7953 \cdot 91]$} & $16.41(1294) * * *$ & \\
\hline Sex & $-1245 \cdot 99$ & {$[-1782 \cdot 11,-709 \cdot 86]$} & $-4 \cdot 56(1294) * * *$ & \\
\hline Year & $146 \cdot 1$ & {$[17 \cdot 78,274 \cdot 42]$} & $2 \cdot 23(1294)^{*}$ & $3.57(5.69)^{* *}$ \\
\hline SDI & $-1498 \cdot 92$ & {$[-1944 \cdot 8,-1053 \cdot 03]$} & $-6 \cdot 59(1294) * * *$ & $32.06(2.35)^{* * *}$ \\
\hline HAQI frontier & $49 \cdot 12$ & {$[-371 \cdot 06,469 \cdot 29]$} & $0 \cdot 23(1294)$ & $2.78(6 \cdot 5)^{* *}$ \\
\hline THS per capita & $-83 \cdot 51$ & {$[-204 \cdot 11,37 \cdot 09]$} & $-1 \cdot 36(1294)$ & $1.91(1.07)$ \\
\hline
\end{tabular}

Adjusted $R$ squared $=0.71 . * p<0 \cdot 05, * * p<0 \cdot 01$, ***p $p<0 \cdot 001$. SDI: socio-demographic index. HAQI frontier: healthcare access and quality index computed based on relationship between HAQI and SDI. THS: total health spending

NCDs attributable to metabolic and behavioral risks, the prevalence rate of diabetes as well as obesity and hypertension were found rising among Fijians, and risk factors of CVDs related to diet, exercise, and smoking had compromised the life expectancy which was similar to the epidemiological transition in developed countries earlier [38]. In the Mongolian population, ischaemic heart disease was found to be associated with advanced age, low intake of fruits or vegetables, and substance use [39]. Concerning NCDs attributable to environmental risks, worse lung function and respiratory disorders were found to be associated with indoor air pollutants from burning biomass fuel for cooking, home dust, animal contact, and smoking in rural areas in Laos [40-42]. In the
Philippines, a study found that around one fifth of a sample were identified as having COPD, and those who had history of tuberculosis, smoking, or used wood fire for cooking had higher odds of the disease [43].

The findings in the literature and the current study implied that the disease burden in terms of YLD rate and mortality rate of NCDs such as CVDs, diabetes, and chronic lung disease attributable to metabolic risks such as hypertension, hyperglycaemia, and obesity; behavioral risks such as dietary risks and substance use; as well as environmental risks such as household air pollution were contributing to longer LHE and shorter life expectancy at $70+$ years particularly in high-risk countries. However, the country

Table 8 Generalized additive mixture models to assess the LHE with respect to YLD rates (per $100 \mathrm{~K}$ ) of risk-cause pairs, for both sexes

\begin{tabular}{|c|c|c|c|c|}
\hline & Estimate & $95 \% \mathrm{CI}$ & $t(d f)$ & $F($ edf $)$ \\
\hline Intercept & $2 \cdot 17$ & {$[2 \cdot 04,2 \cdot 31]$} & $31 \cdot 39(1586) * * *$ & \\
\hline YLD (Met, CMNND) & $-0 \cdot 32$ & {$[-0 \cdot 52,-0 \cdot 11]$} & $-3.03(1586)^{* *}$ & $4 \cdot 22(6 \cdot 28)^{* * *}$ \\
\hline YLD (Met, NCD) & $0 \cdot 25$ & {$[0 \cdot 15,0 \cdot 36]$} & $4 \cdot 62(1586)^{* * *}$ & $13.67(1.92)^{* * *}$ \\
\hline YLD (Met, Inj) & $0 \cdot 2$ & {$[0 \cdot 12,0 \cdot 29]$} & $4.91(1586)^{* * *}$ & $24 \cdot 13(1) * * *$ \\
\hline YLD (Env/Occ, CMNND) & $0 \cdot 02$ & {$[-0 \cdot 08,0 \cdot 13]$} & $0 \cdot 47(1586)$ & $0 \cdot 22(1)$ \\
\hline YLD (Env/Occ, NCD) & $0 \cdot 01$ & {$[-0.08,0.09]$} & $0 \cdot 16(1586)$ & $0 \cdot 02(1)$ \\
\hline YLD (Env/Occ, Inj) & $0 \cdot 77$ & {$[0.69,0.86]$} & $17.77(1586) * * *$ & $74.64(8.88)^{* * *}$ \\
\hline YLD (Beh, CMNND) & $-0 \cdot 18$ & {$[-0 \cdot 34,-0 \cdot 03]$} & $-2 \cdot 28(1586)^{*}$ & $3.93(3.35)^{* *}$ \\
\hline YLD (Beh, NCD) & $-0 \cdot 11$ & {$[-0 \cdot 37,0 \cdot 14]$} & $-0 \cdot 87(1586)$ & $6 \cdot 33(6 \cdot 8)^{* * *}$ \\
\hline YLD (Beh, Inj) & $-0 \cdot 08$ & {$[-0 \cdot 22,0 \cdot 05]$} & $-1 \cdot 24(1586)$ & $1.62(2.44)$ \\
\hline
\end{tabular}

Adjusted $R$ squared $=0.47$. $* p<0.05, * * p<0.01, * * * p<0.001$. Model was adjusted for years and clusters. LHE: equivalent lost healthy years. YLD: years lived with disability. Met: metabolic risks (i.e., high fasting plasma glucose; high cholesterol; high blood pressure; high BMI; low bone mineral density; impaired kidney function). Env/Occ: environmental/occupational risks (i.e., unsafe water; sanitation; handwashing; air pollution; exposure to occupational carcinogens). Beh: behavioral risks (i.e., child \& maternal malnutrition; tobacco use; alcohol use; drug use; dietary risks; intimate partner violence; childhood maltreatment; unsafe sex; low physical activity). CMNND: communicable, maternal, neonatal and nutritional diseases. NCD: non-communicable disease. Inj: injuries 
Table 9 Generalized additive mixture models to assess life expectancy with respect to mortality rates (per $100 \mathrm{~K}$ ) of risk-cause pairs, for both sexes

\begin{tabular}{|c|c|c|c|c|}
\hline & Estimate & $95 \% \mathrm{CI}$ & $t(d f)$ & $\mathrm{F}(\mathrm{edf})$ \\
\hline Intercept & $7 \cdot 24$ & {$[7 \cdot 03,7 \cdot 45]$} & $67.67(1586)^{* * *}$ & \\
\hline Mortality (Met, CMNND) & $-0 \cdot 03$ & {$[-0 \cdot 13,0.06]$} & $-0 \cdot 69(1586)$ & $0 \cdot 3(1 \cdot 26)$ \\
\hline Mortality (Met, NCD) & $-0 \cdot 42$ & {$[-0 \cdot 67,-0 \cdot 17]$} & $-3 \cdot 26(1586)^{* *}$ & $14.45(7.06)^{* * *}$ \\
\hline Mortality (Met, Inj) & $-0 \cdot 36$ & {$[-1 \cdot 24,0 \cdot 53]$} & $-0 \cdot 79(1586)$ & $38.11(7.08)^{* * *}$ \\
\hline Mortality (Env/Occ, CMNND) & $-0 \cdot 82$ & {$[-1 \cdot 1,-0 \cdot 53]$} & $-5.61(1586)^{* * *}$ & $6 \cdot 85(7.95)^{* * *}$ \\
\hline Mortality (Env/Occ, NCD) & $0 \cdot 17$ & {$[-0 \cdot 15,0 \cdot 49]$} & $1.06(1586)$ & $1 \cdot 84(6 \cdot 65)$ \\
\hline Mortality (Env/Occ, Inj) & $-0 \cdot 003$ & {$[-0.03,0.02]$} & $-0 \cdot 25(1586)$ & $0 \cdot 06(1)$ \\
\hline Mortality (Beh, CMNND) & $-0 \cdot 13$ & {$[-0 \cdot 24,-0 \cdot 02]$} & $-2 \cdot 31(1586)^{*}$ & $5 \cdot 34(1)^{*}$ \\
\hline Mortality (Beh, NCD) & $-1 \cdot 88$ & {$[-2 \cdot 3,-1 \cdot 45]$} & $-8.66(1586)^{* * *}$ & $18 \cdot 2(8 \cdot 75)^{* * *}$ \\
\hline Mortality (Beh, Inj) & $-1 \cdot 62$ & {$[-2 \cdot 18,-1 \cdot 06]$} & $-5.66(1586) * * *$ & $94.4(8.85)^{* * *}$ \\
\hline
\end{tabular}

Adjusted $R$ squared $=0.84$. $* p<0.05, * * p<0.01$, ***p $<0.001$. Model was adjusted for years and clusters. Met: metabolic risks (i.e., high fasting plasma glucose; high cholesterol; high blood pressure; high BMI; low bone mineral density; impaired kidney function). Env/Occ: environmental/occupational risks (i.e., unsafe water; sanitation; handwashing; air pollution; exposure to occupational carcinogens). Beh: behavioral risks (i.e., child \& maternal malnutrition; tobacco use; alcohol use; drug use; dietary risks; intimate partner violence; childhood maltreatment; unsafe sex; low physical activity). CMNND: communicable, maternal, neonatal and nutritional diseases. NCD: non-communicable disease. Inj: injuries

cluster was not a significant independent variable of either LHE or life expectancy when time and either YLD rate or mortality rate were statistically controlled for (data not shown in text). Furthermore, the number of years lived in poor health has been growing over the years [1]. Thus, the control of NCDs and their risks should have a high priority in lowering the LHE fraction at older ages.

A final comment is directed towards government health spending and THS per GDP in Pacific Island countries, which were inconsistent over the years, with total health spending at the same time being at a low level. The governments of these countries need to rethink their health spending in a more consistent way and direct more health spending on the areas of higher priority as shown in the results of this analysis, including health promotion programmes in older people related to NCDs. This may include, among other things, specific strategies for a more concrete integration of traditional medicine, which is the main primary health care in many of the communities on Pacific Islands [44, 45].

The findings of our work have a dual set of policy implications. First, it will help Western Pacific countries with a high percentage of aged residents plan, develop, and implement health intervention programmes in order to address and reduce the burden of disability and mortality among older adults. Second, it will help other specific Western Pacific regions, such as low- and middle-income ones, better prepare their preventive strategies and public health systems for future health needs due to the rapid demographic changes.

\section{Limitations}

All limitations of the GBD 2019 publications are also applicable to this study [7, 9, 10], mostly the challenges of capturing sources of uncertainty, lags in data availability, variation in coding practices and other biases, and limitations of existing analytical tools, which may not fully capture temporal analysed trends among the Western Pacific Region countries. Available data sources for the GBD population included, among others surveys, censuses adjusted and unadjusted, and WHO vital registration systems. Additional limitations are that the data analysis could not adjust for other factors influencing LE, HALE, population mortality and YLDs, as for example genetic factors, adherence to specific medication) and changes in the treatment that could also alter the presented estimations. Also, accumulated comorbidities is a common phenomenon in older adults [46], however the nature of GBD data does not allow to account for accumulated comorbidities, an issue that may further limit the true magnitude of our findings. GAM models were tested also without taking into account clusters and equivalent results were confirmed (data not shown in text). As this is 
a descriptive study, while we analyse a number of correlates and associations among the variables of interest, our analyses cannot conclude causal relationships. Finally, the applied modelling methodologies in this study may not capture fully the trends and patterns of disease burden among older adults living in WPRs.

\section{Conclusion}

The sociodemographic and socioeconomic development was found a more important factor to the disease burden in terms of YLD rate and mortality rate among older adults than the health spending in the Western Pacific Region. However, proximal predictors of YLD rate and mortality rate need to be identified with country-specific parameters estimated to outline a global picture with respect to levels of modifiable risk factors. YLD and mortality of NCDs attributable to certain risks were identified as significant contributors to longer LHE and shorter life expectancy respectively in the context of rising YLD rate. Sub-regional health planning and interventions should be developed and prioritized based on cluster-specific characteristics and disease burden to lower LHE fraction and probably lengthen life expectancy and HALE at $70+$ in the Western Pacific Region. Evidence-based work on successful ageing is completely missing from the Pacific Islands [47] as well as much of the developing countries in this region. Leaders of LMICs need to have vision and plan to promote heath knowledge and awareness at personal and governmental levels which is supported with social advancements. Hence, governments and policy makers in the region need to urgently prioritise "healthy ageing" as has been done in other developed countries globally, as both life expectancy is steadily increasing and the burden of NCDs alongside other health risk factors is also growing.

Author contribution Managing the overall research enterprise: AM. Managing the analysis process: SWHK. Extracting, cleaning, or cataloguing data: SWHK. Providing data or critical feedback on data sources: SWHK, ST, AYML, AM. Developing methods or computational machinery: SWHK. Applying analytical methods to produce results: SWHK. Providing critical feedback on methods or results: AM, AYML, ST. Designing or coding figures and tables: SWHK. Writing the first draft of the manuscript: SWHK, AM. Drafting the work or revising it critically for important intellectual content: AM, AYML, ST.
Data availability To download the data used in these analyses, please visit the Global Health Data Exchange GBD 2020 website.

Code availability N/A.

Declarations

Ethics approval NA. Analysis of data from an open database.

Consent to participate N/A

Consent for publication N/A

Conflict of interest The authors declare no competing interests.

Open Access This article is licensed under a Creative Commons Attribution 4.0 International License, which permits use, sharing, adaptation, distribution and reproduction in any medium or format, as long as you give appropriate credit to the original author(s) and the source, provide a link to the Creative Commons licence, and indicate if changes were made. The images or other third party material in this article are included in the article's Creative Commons licence, unless indicated otherwise in a credit line to the material. If material is not included in the article's Creative Commons licence and your intended use is not permitted by statutory regulation or exceeds the permitted use, you will need to obtain permission directly from the copyright holder. To view a copy of this licence, visit http://creativecommons.org/licenses/by/4.0/.

\section{References}

1. GBD 2019 Demographics Collaborators. Global agesex-specific fertility, mortality, healthy life expectancy (HALE), and population estimates in 204 countries and territories, 1950-2019: A comprehensive demographic analysis for the Global Burden of Disease Study 2019. Lancet. 2020; 396(10258): 1160-203.

2. Molassiotis A, Leung AYM, Zhao IY. Call for urgent actions in societies and health systems in the Western Pacific Region to implement the WHO Regional Action Plan on Healthy Ageing. J Am Geriatr Soc. 2021;69(8):2374-7.

3. OECD. Health-care reform in Japan: Controlling costs, improving quality and ensuring equity. OECD Economic Surveys. 2009;2009(18):99.

4. United Nations. 2019 Human Development Index ranking. 2020. http://hdr.undp.org/en/content/2019-human-devel opment-index-ranking (accessed 12th June 2020).

5. Global Burden of Disease Collaborative Network. Global Burden of Disease Study 2019 (GBD 2019) Socio-Demographic Index (SDI) 1950-2019. Seattle, United States of America: Institute for Health Metrics and Evaluation (IHME); 2020.

6. WHO Department of Health Statistics and Information Systems. WHO methods for life expectancy and healthy 
life expectancy. Geneva: World Health Organization; 2014.

7. GBD 2019 Diseases and Injuries Collaborators. Global burden of 369 diseases and injuries in 204 countries and territories, 1990-2019: A systematic analysis for the Global Burden of Disease Study 2019. Lancet. 2020; 396(10258): 1204-22.

8. World Health Organization. Metrics: Disability-adjusted life year (DALY). 2020. https://www.who.int/healthinfo/ global_burden_disease/metrics_daly/en/ (accessed 24th May 2020).

9. GBD 2019 Risk Factors Collaborators. Global burden of 87 risk factors in 204 countries and territories, 1990-2019: a systematic analysis for the Global Burden of Disease Study 2019. Lancet. 2020; 396(10258): 1223-49.

10. Global Burden of Disease Health Financing Collaborator Network. Past, present, and future of global health financing: A review of development assistance, government, out-of-pocket, and other private spending on health for 195 countries, 1995-2050. Lancet. 2019;393(10187):2233-60.

11. Global Burden of Disease Health Financing Collaborator Network. Spending on health and HIV/AIDS: Domestic health spending and development assistance in 188 countries, 1995-2015. Lancet. 2018;391(10132):1799-829.

12. Shibuya K, Hashimoto H, Ikegami N, et al. Japan: Universal Health Care at 50 Years 6 Future of Japan's system of good health at low cost with equity: Beyond universal coverage. Lancet. 2011;378(9798):1265-73.

13. Hashimoto H, Ikegami N, Shibuya K, et al. Japan: Universal Health Care at 50 years 3 Cost containment and quality of care in Japan: Is there a trade-off? Lancet. 2011;378(9797):1174-82.

14. Yusuf F, Leeder SR. Can't escape it: The out-ofpocket cost of health care in Australia. Med J Aust. 2013;199(7):475-8.

15. Capuno JJ, Kraft AD, Poco LC, Quimbo SA, Tan CAR. Health conditions, payments, proximity, and opportunity costs: Examining delays in seeking inpatient and outpatient care in the Philippines. Soc Sci Med. 2019;238:112479.

16. Tang S, Tao J, Bekedam H. Controlling cost escalation of healthcare: Making universal health coverage sustainable in China. BMC Public Health 2012; 12(1): S8-S.

17. Zhou Q, Liu GG, Sun Y, Vortherms SA. The impact of health insurance cost-sharing method on healthcare utilisation in China. China J Soc Work. 2016;9(1):38-61.

18. Zhai T, Goss J, Dmytraczenko T, Zhang Y, Li J, Chai P. China's health expenditure projections to 2035: Future trajectory and the estimated impact of reforms. Health Aff. 2019;38(5):835-43.

19. GBD 2016 Causes of Death Collaborators. Global, regional, and national age-sex specific mortality for 264 causes of death, 1980-2016: A systematic analysis for the Global Burden of Disease Study 2016. Lancet. 2017; 390(10100): 1151-210.

20. GBD 2016 Disease and Injury Incidence and Prevalence Collaborators. Global, regional, and national incidence, prevalence, and years lived with disability for 328 diseases and injuries for 195 countries, 1990-2016: A systematic analysis for the Global Burden of Disease Study 2016. Lancet 2017; 390(10100): 1211-59.

21. Sullivan DF. A Single Index of Mortality and Morbidity. HSMHA Health Reports. 1971;86(4):347-54.

22. Flaxman AD, Vos T, Murray CJL. An integrative metaregression framework for descriptive epidemiology. Seattle: University of Washington; 2015.

23. Salomon JA, Vos T, Hogan DR, et al. Common values in assessing health outcomes from disease and injury: Disability weights measurement study for the Global Burden of Disease Study 2010. Lancet. 2012;380(9859):2129-43.

24. Salomon JA, Haagsma JA, Davis A, et al. Disability weights for the Global Burden of Disease 2013 study. Lancet Glob Health. 2015;3(11):e712-23.

25. Institute for Health Metrics and Evaluation (IHME). Global Educational Attainment Distributions 1970-2030. Seattle, United States of America: Institute for Health Metrics and Evaluation (IHME); 2020.

26. Global Burden of Disease Collaborative Network. Global Burden of Disease Study 2019 (GBD 2019) Fertility Estimates 1950-2019. . Seattle, United States of America: Institute for Health Metrics and Evaluation (IHME); 2020.

27. World Bank Data Team. New country classifications by income level: 2018-2019. 2018. https://blogs.worldbank. org/opendata/new-country-classifications-income-level2018-2019 (accessed June 19 2019).

28. GBD 2015 Healthcare Access and Quality Collaborators. Healthcare Access and Quality Index based on mortality from causes amenable to personal health care in 195 countries and territories, 1990-2015: A novel analysis from the Global Burden of Disease Study 2015. Lancet 2017; 390(10091): 231-66.

29. Global Burden of Disease Collaborative Network. Global Health Spending 1995-2017. Seattle, United States of America: Institute for Health Metrics and Evaluation (IHME); 2020.

30. Global Burden of Disease Collaborative Network. Global Expected Health Spending 2018-2050. Seattle, United States of America: Institute for Health Metrics and Evaluation (IHME); 2020.

31. Clifford GD. The use of sustainable and scalable health care technologies in developing countries. Innovation and Entrepreneurship in Health. 2016;3:35.

32. Peabody JW, Tozija F, Muñoz JA, Nordyke RJ, Luck J. Using vignettes to compare the quality of clinical care variation in economically divergent countries. Health Services Research. 2004;39(6p2):1951-70.

33. Schwappach DLB. Risk factors for patient-reported medical errors in eleven countries. Health Expect. 2014;17(3):321-31.

34. McMaughan DJ, Oloruntoba O, Smith ML. Socioeconomic status and access to healthcare: Interrelated drivers for healthy aging. Front Public Health 2020; 8: 231-.

35. Sullivan K, Thakur N. Structural and social determinants of health in asthma in developed economies: A scoping review of literature published between 2014 and 2019. Curr Allergy Asthma Rep. 2020;20(2):5.

36. Brown AF, Ma GX, Miranda J, et al. Structural interventions to reduce and eliminate health disparities. Am J Public Health. 2019;109(S1):S72-8. 
37. Institute for Health Metrics and Evaluation. GBD results tool. 2020. http://ghdx.healthdata.org/gbd-results-tool (accessed 24th May 2020).

38. Taylor R, Lin S, Linhart C, Morrell S. Overview of trends in cardiovascular and diabetes risk factors in Fiji. Ann Hum Biol. 2018;45(3):188-201.

39. Enkh-Oyun T, Kotani K, Davaalkham D, et al. Ischemic heart disease and its related factors in Mongolia: A nationwide survey. J Community Health. 2013;38(5):919-25.

40. Mengersen K, Morawska L, Wang H, et al. The effect of housing characteristics and occupant activities on the respiratory health of women and children in Lao PDR. Sci Total Environ. 2011;409(8):1378-84.

41. Mengersen K, Morawska L, Wang H, et al. Association between indoor air pollution measurements and respiratory health in women and children in Lao PDR: Indoor air and respiratory health in Lao PDR. Indoor Air. 2011;21(1):25-35.

42. Lopez JR, Somsamouth K, Mounivong B, et al. Environmental exposures, lung function, and respiratory health in rural Lao PDR. Southeast Asian J Trop Med Public Health. 2014;45(1):198-206.

43. Idolor LF, De Guia TS, Francisco NA, et al. Burden of obstructive lung disease in a rural setting in the Philippines. Respirology. 2011;16(7):1111-8.
44. Chung VCH, Wong CHL, Zhong CCW, Tjioe YY, Leung TH, Griffiths SM. Traditional and complementary medicine for promoting healthy ageing in WHO Western Pacific Region: Policy implications from utilization patterns and current evidence. Integrative Medicine Research 2021; 10(1): 100469-.

45. Park YL, Canaway R. Integrating traditional and complementary medicine with national healthcare systems for universal health coverage in Asia and the Western Pacific. Health Systems \& Reform. 2019;5(1):24-31.

46. Garin N, Koyanagi A, Chatterji S, Tyrovolas S, Olaya B, Leonardi M, Lara E, Koskinen S, Tobiasz-Adamczyk B, Ayuso-Mateos JL, Haro JM. Global Multimorbidity Patterns: A Cross-Sectional, Population-Based, Multi-Country Study. J Gerontol A Biol Sci MedSci. 2016;71(2):205-14.

47. Reich AJ, Claunch KD, Verdeja MA, et al. What does "successful aging" mean to you? - systematic review and cross-cultural comparison of lay perspectives of older adults in 13 countries, 2010-2020. J Cross Cult Gerontol. 2020;35(4):455-78.

Publisher's note Springer Nature remains neutral with regard to jurisdictional claims in published maps and institutional affiliations. 